Jamille Baultar Costa

(iD) https://orcid.org/0000-0003-1504-9037

Mônica Angelim Gomes de Lima

(iD) https://orcid.org/0000-0003-3364-8439

Robson da Fonseca Neves

iD https://orcid.org/0000-0002-3889-560X

a Universidade Federal da Bahia (UFBA), Faculdade de Medicina da Bahia, Programa de Pós-Graduação em Saúde, Ambiente e Trabalho. Salvador BA, Brasil.

b Universidade Federal da Paraíba (UFPB), Departamento de Fisioterapia. Programa de Pós-Graduação em Fisioterapia. João Pessoa, PB, Brasil.

Contato:

Jamille Baultar Costa

E-mail:

baultar@gmail.com

Os autores declaram que o trabalho não foi subvencionado e que não há conflitos de interesses.

Os autores informam que o trabalho não foi apresentado em evento científico.

Manuscrito baseado na dissertação de mestrado Sobreviventes: os significados do retorno ao trabalho após a experiência do câncer de mama, de Jamille Baultar Costa, apresentada em 2017 ao Programa de Pós-Graduação em Saúde, Ambiente e Trabalho, da Faculdade de Medicina da Universidade Federal da Bahia.

\section{$O$ retorno ao trabalho de mulheres após a experiência do câncer de mama: uma metassíntese}

\author{
Women's return to work after \\ experiencing breast cancer: a metasynthesis
}

\section{Resumo}

Introdução: o câncer de mama (CM) é a neoplasia mais comum em mulheres no mundo e o número de casos vem aumentando na população economicamente ativa. Por isso, o retorno ao trabalho após CM tem despertado interesse da comunidade científica. Objetivo: sistematizar e sintetizar os estudos qualitativos que abordam a experiência do retorno ao trabalho após o CM. Métodos: metassíntese qualitativa com busca dos estudos primários nas bases ASSIA, BIREME, CINAHL, Embase, PsycInfo, SciELO, Scopus e Web of Science. Foram localizados 779 artigos, dos quais, nove atenderam aos critérios de seleção. Resultados: seis conceitos de segunda ordem foram gerados: os efeitos da doença na reabilitação; questões financeiras; medo de recidivas; apoio da família, amigos e profissionais de saúde; e mudanças do significado do trabalho após CM. Conclusão: o retorno ao trabalho não deve se limitar aos aspectos relacionados aos obstáculos e facilitadores da reabilitação Os "mundos da vida" evidenciados nos fatores contextuais mais abrangentes revelam que o enfrentamento do retorno ao trabalho implica no aprimoramento do suporte às trabalhadoras no ambiente de trabalho, na vida familiar, na relação com os sistemas de saúde e seguridade social e na esfera individual, a fim de prevenir aposentadorias precoces e incapacidade prolongada.

Palavras-chave: metassíntese; retorno ao trabalho; câncer de mama; mulheres trabalhadoras; saúde do trabalhador.

\begin{abstract}
Introduction: breast cancer $(B C)$ is the most common cancer in women worldwide and the number of cases has increased among the economically active population. Therefore, issues related to returning to work after BC has aroused the interest of the scientific community. Objective: To systematize and synthesize qualitative studies that address the experience of returning to work after BC. Methods: qualitative meta-synthesis with search for primary studies in ASSIA, BIREME, CINAHL, Embase, PsycInfo, SciELO, Scopus and Web of Science databases. The total of 779 articles were found, of which only nine met the inclusion criteria. Results: six second-order concepts were generated: the effects of the disease on rehabilitation; financial problems; fear of recurrences; support from family, friends and health professionals; and changes in the meaning of work after BC. Conclusion: the return to work should not be limited to aspects related to obstacles and facilitators of rehabilitation. The "worlds of life" shown in the broader contextual factors reveal that facing the return to work implies improving support for workers in the work environment, in family life, in the relationship with the health and social security systems and in the individual sphere, to prevent early retirements and prolonged disability.
\end{abstract}

Keywords: metasynthesis; return to work; breast cancer; working women; occupational health. 


\section{Introdução}

O câncer de mama (CM) é a neoplasia que possui a maior incidência na população feminina mundial. Em 2012, ele representou 25\% de todos os tipos de câncer diagnosticados nas mulheres e 15\% de todas as mortes por câncer em mulheres no planeta ${ }^{1,2}$. No Brasil, estimou-se para cada ano do biênio 2018-2019, 59.700 casos novos de CM, com um risco estimado de 56,33 casos a cada 100 mil mulheres ${ }^{2}$.

O diagnóstico precoce, as tecnologias relacionadas ao tratamento e as mobilizações sociais no enfrentamento da doença são algumas das mudanças na abordagem do CM das três últimas décadas ${ }^{3}$.

As transformações vivenciadas pelas "sobreviventes do câncer de mama" (nomenclatura dada pela literatura especializada para mulheres que resistem ao tratamento da doença ${ }^{4}$ ), têm sido investigadas, principalmente, no que se refere à experiência de se afastar do trabalho e, posteriormente, retornar às atividades laborativas ${ }^{5}$. Nesse sentido, o retorno ao trabalho (RT) tem se configurado como um objeto importante, pois, o voltar a ser produtiva tem um valor simbólico que se contrapõe ao rótulo de incapacidade conferido pelas condições crônicas de saúde em geral. Mais que isso, representa também inclusão social ${ }^{6}$.

Por outro lado, ainda são insuficientes os conhecimentos sobre os facilitadores e obstáculos enfrentados por trabalhadoras que se afastam devido ao $\mathrm{CM}$ e posteriormente voltam a trabalhar ${ }^{7}$. Isso porque o RT precisa ser investigado para além de seus resultados exitosos ou não, medidos por: intensidade da dor, capacidade física, capacidade psíquica, permanência no emprego com limitações e estresse no ambiente laboral ${ }^{8}$.

Sabe-se que mudanças na carga horária semanal, realização de outras tarefas ou redução de atividades físicas ou mentais, o auxílio dos colegas e gestores e as alterações estruturais e organizacionais no ambiente de trabalho têm sido estratégias utilizadas pelas sobreviventes do CM para gerenciar as limitações no $\mathrm{RT}^{4}$. No entanto, questões referentes ao retorno ao trabalho dependem de uma interação complexa de fatores individuais e ambientais ${ }^{9}$ que também precisam ser melhor compreendidas para apoiar as trabalhadoras com CM na sua retomada das atividades laborais ${ }^{10}$.
Este trabalho tem como objetivo sistematizar e sintetizar os estudos qualitativos que abordam a experiência do RT após o CM e compreender os elementos, tidos como facilitadores ou obstáculos, presentes nesse processo.

\section{Métodos}

Adotou-se o modelo de Young et al. ${ }^{11}$, que toma o RT como processo, para orientar esta pesquisa. Destarte, quando do retorno ao contexto laboral, o trabalhador deveriam passar por fases não lineares que incluiriam o enfrentamento da lesão ou doença crônica fora do trabalho (off work), a reentrada propriamente dita com estabelecimento de metas acordadas entre empregado e empregador (re-entry), a manutenção do empregado no ambiente de trabalho (maintenance) e o progresso no trabalho incluindo o avanço na carreira até a sua aposentadoria no tempo certo (advancement). Esse processo reforça a suposição de que as experiências de quem se afastou do trabalho por causa do CM podem revelar aspectos específicos a depender da fase em que a pessoa se encontre no RT.

O desenho de estudo utilizado neste trabalho foi a metassíntese qualitativa. Trata-se de uma abordagem metodológica onde pesquisas qualitativas empíricas têm seus achados comparados e sintetizados a fim de produzir uma nova síntese sobre determinado tema ${ }^{12,13}$. Esta metodologia permite a clarificação de conceitos, pois resulta num refinamento do estado do conhecimento, tendo o potencial de aprimorar saberes além de fornecer informações que subsidiarão novas pesquisas e a agenda de debates sobre determinados temas de interesse público ${ }^{14}$.

\section{Estratégia de pesquisa e critérios de inclusão}

A busca dos estudos envolveu as seguintes bases de dados: ASSIA, BIREME, CINAHL, Embase, PsycInfo, SciELO, Scopus e Web of Science (WoS). A escolha dessas bases foi em razão da abrangência de publicações na área da saúde e suas interações com aspectos políticos, sociais, econômicos e culturais que também cercam o problema em questão (Figura 1). Foi estabelecido como recorte temporal, artigos publicados entre janeiro de 1999 a janeiro de 2015, utilizando como descritores: "breast cancer" combinado pelo operador booleano "AND" com "return to work" (ambos os termos indexados pelos Medical Subject Headings (MeSH)). 
Passo 1: Busca sistemática da literatura

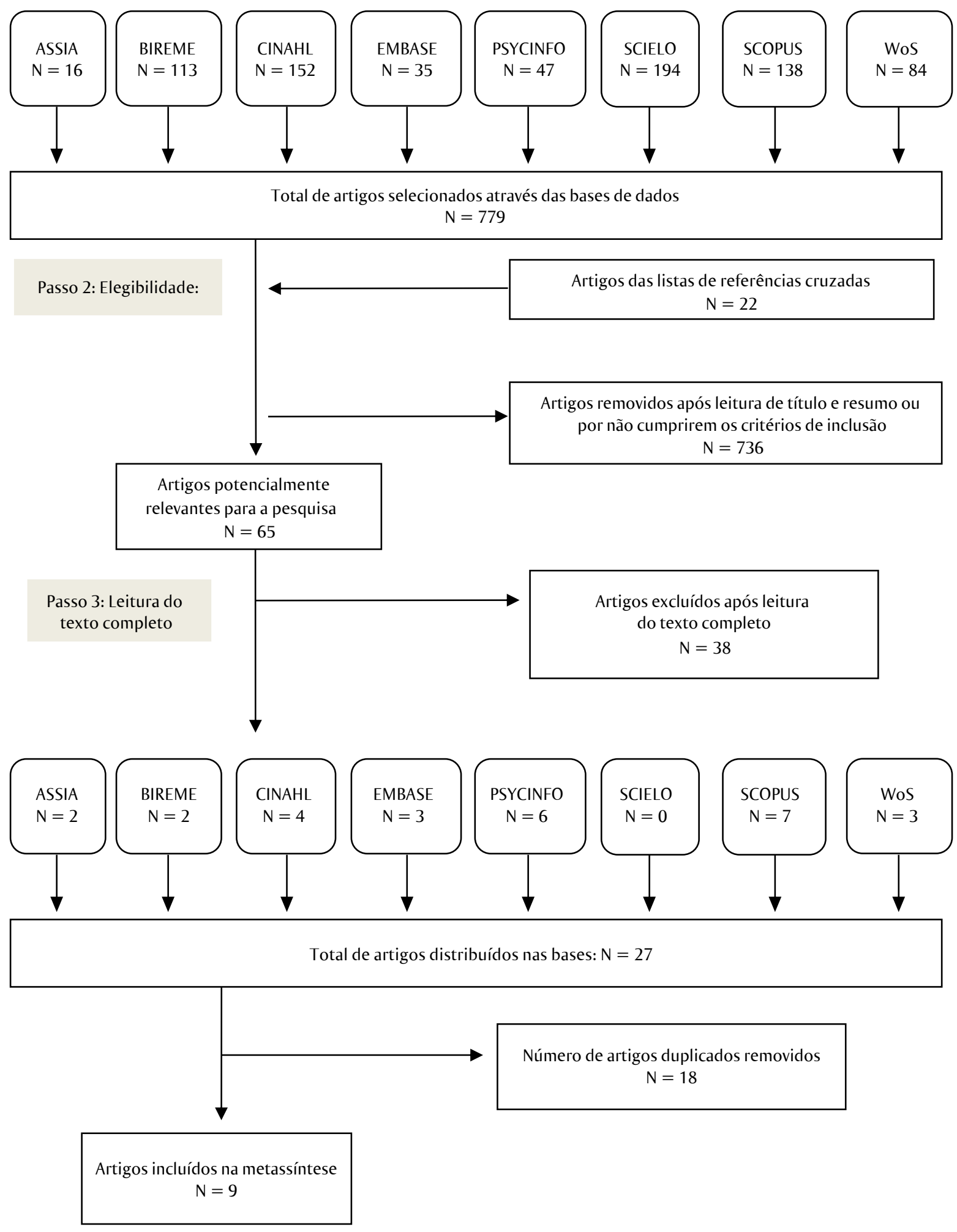

Figura 1 Fluxograma de seleção dos artigos 
Foram identificados 779 artigos originais, completos, publicados em inglês, revisados por pares. Nas bases eles estavam assim distribuídos: ASSIA: 16, BIREME: 113, CINAHL: 152, Embase: 35, PsycInfo: 47, SciELO: 194, Scopus: 138, WoS: 84. Também foram adicionados artigos relevantes sobre o tema localizados nas referências dos artigos incluídos, através de busca manual. Como critérios de inclusão, foram selecionados estudos qualitativos que tratavam do RT de sobreviventes do CM. Foram excluídos artigos que abordavam o ingresso no mercado de trabalho de pessoas que tiveram câncer, mas que não estavam trabalhando antes da doença e artigos que tratavam de RT de pessoas com múltiplos tipos de câncer, incluindo o CM.

Os trabalhos foram selecionados inicialmente pelos seus títulos e resumos, e, após verificar se os artigos cumpriam os critérios de elegibilidade, a leitura do texto completo foi realizada por dois pesquisadores. Nos casos divergentes, um terceiro pesquisador com experiência em pesquisas qualitativas no campo da saúde do trabalhador auxiliou na solução do impasse.

Após a retirada das duplicatas pelo sistema de gerenciamento de documentos em PDF e organizador de referências Mendeley 1.12.1 versão livre para Windows, os estudos incluídos foram submetidos a avaliação de qualidade por meio do Critical Appraisal Skills Programme (CASP) ${ }^{15}$ e tiveram seu rigor metodológico avaliado pelo Consolidated Criteria for Reporting Qualitative Research (COREQ) ${ }^{16}$.

Foram considerados artigos de qualidade aqueles que atendessem todos os temas do CASP e que atingissem o maior número de itens contidos em cada domínio do COREQ. Ao final, os artigos que atenderam às exigências do CASP e do COREQ e que cumpriram os critérios de elegibilidade foram submetidos ao processo de análise.

\section{Análise dos dados}

Os dados foram análisados através da Tradução Recíproca como Síntese desenvolvida por Noblit e Hare ${ }^{17}$. Traduções recíprocas são geradas pela leitura repetida e interpretação dos conceitos de primeira ordem encontrados nos artigos originais, os quais, após analisados, forneceram os temas de onde se extrai a síntese ${ }^{7}$.

O método, descrito por Neves, Nunes e Magalhães ${ }^{12}$, que envolve três ordens de organização e análise dos dados, foi utilizado para guiar esta metassíntese: a primeira ordem envolveu o reconhecimento dos conceitos contidos nos artigos originais, a segunda ordem correspondeu ao processo interpretativo a partir da comparação dos achados que se repetem em pelo menos dois estudos originais e a terceira ordem ou síntese consistiu numa reinterpretação dos conceitos de segunda ordem em relação às questões que guiam o objeto de estudo e as teorias e/ou conceitos que suscitaram desse novo sentido. Dois pesquisadores experientes examinaram o processo de síntese e avaliaram as construções de terceira ordem para confirmar se foi produzida uma reconceitualização final que refletisse os achados de primeira e segunda ordem ${ }^{8}$.

Tomamos a noção de contexto de Patricia Munhall ${ }^{18}$ descrita como uma unidade inter-relacional daquilo que ela chama "mundos da vida", a saber: a espacialidade, a corporalidade, a temporalidade e a relacionalidade para guiar a organização do material de análise dessa metassíntese. Para Munhall, corporalidade se refere tanto ao corpo que habitamos como à própria ideia que temos de nossos corpos. Já a espacialidade é compreendida como o material fenomenológico que precisa ser processado através da lente do ambiente. A relacionalidade consiste nos nossos encontros com os outros que são construídos e reconstruídos em contextos dinâmicos que dependem das relações sociais formadas e das contingências singulares que são vivenciadas ao longo dessa jornada, enquanto a temporalidade representa a forma como experienciamos nossos corpos encarnados, ocupando espaços localizados no tempo, mas que muitas vezes podem trazer ao tempo do mundo da vida experiências já vividas e aquelas que ainda queremos vir a ter ${ }^{18}$.

Dessa forma, ao utilizar a fenomenologia hermenêutica para sustentar essa metassíntese, entende-se que esse referencial fornece uma compreensão daquilo que foi interpretado nos estudos originais compondo agora uma reinterpretação do contexto ou dos mundos da vida, no qual se deu o RT de trabalhadoras sobreviventes do $\mathrm{CM}^{19,20}$.

\section{Resultados}

Nove artigos cumpriram os critérios de elegibilidade (Quadro 1), atenderam às exigências do CASP (Quadro 2) e do COREQ (Quadro 3) e foram submetidos ao processo de análise. 
Quadro 1 Descrição dos artigos selecionados na metassíntese de estudos sobre retorno ao trabalho de mulheres com câncer de mama

\begin{tabular}{|c|c|c|c|c|c|}
\hline $\begin{array}{l}\text { Autores } \\
\text { (país) }\end{array}$ & Objetivo do estudo & Participantes & Coleta de dados & Método de análise & $\begin{array}{c}\text { Barreiras e Facilitadores do } \\
\text { RT após CM }\end{array}$ \\
\hline $\begin{array}{l}\text { Maunsell, } \\
\text { et al. }{ }^{21} \\
\text { (Canadá) }\end{array}$ & $\begin{array}{l}\text { Fornecer uma } \\
\text { visão da natureza } \\
\text { dos problemas } \\
\text { do trabalho } \\
\text { percebidos por } \\
\text { mulheres após } \\
\text { o câncer de } \\
\text { mama que foram } \\
\text { tratadas com novas } \\
\text { modalidades de } \\
\text { tratamento. }\end{array}$ & $\begin{array}{l}\text { Treze sobreviventes } \\
\text { de câncer da mama } \\
\text { que tinham empregos } \\
\text { remunerados } \\
\text { no momento do } \\
\text { diagnóstico e que } \\
\text { voltaram a trabalhar } \\
\text { depois do tratamento } \\
\text { da doença. }\end{array}$ & $\begin{array}{l}\text { Entrevistas } \\
\text { temáticas } \\
\text { semiestruturadas }\end{array}$ & $\begin{array}{l}\text { Análise de } \\
\text { conteúdo } \\
\text { temático segundo } \\
\text { Deslauriers e } \\
\text { L'Ecuyer. }\end{array}$ & $\begin{array}{l}\text { Barreiras: alterações indesejadas } \\
\text { em tarefas, problemas com } \\
\text { empregador e colegas de trabalho, } \\
\text { diminuição da capacidade física, } \\
\text { pouco diálogo com o médico } \\
\text { sobre os impactos da doença/ } \\
\text { tratamentos para o RT. } \\
\text { Facilitadores: o apoio dos colegas } \\
\text { foi positivo, a conscientização do } \\
\text { diagnóstico para o gestor e colegas } \\
\text { de trabalho. }\end{array}$ \\
\hline $\begin{array}{l}\text { Kennedy } \\
\text { et al. }{ }^{22} \\
\text { (Reino } \\
\text { Unido) }\end{array}$ & $\begin{array}{l}\text { Explorar os fatores } \\
\text { que influenciam } \\
\text { as decisões dos } \\
\text { pacientes com } \\
\text { câncer de voltar } \\
\text { ao trabalho e a } \\
\text { experiência de } \\
\text { voltar a trabalhar. }\end{array}$ & $\begin{array}{l}29 \text { mulheres que } \\
\text { receberam o } \\
\text { diagnóstico de } \\
\text { câncer de mama ao } \\
\text { longo de } 10 \text { anos } \\
\text { com idade de } 36 \text { a } \\
66 \text { anos. }\end{array}$ & $\begin{array}{l}\text { Entrevistas } \\
\text { semiestruturadas } \\
\text { e grupos focais }\end{array}$ & $\begin{array}{l}\text { Entrevistas } \\
\text { analisadas pelo } \\
\text { método descrito } \\
\text { por Silverman e os } \\
\text { dados do grupo de } \\
\text { focal analisados } \\
\text { pelo método de } \\
\text { Knodel. }\end{array}$ & $\begin{array}{l}\text { Barreiras: necessidade de } \\
\text { mais aconselhamento dos } \\
\text { profissionais de saúde sobre o RT, } \\
\text { juntamente com o apoio razoável e } \\
\text { ajustes por parte dos empregadores. } \\
\text { Facilitadores: flexibilidade, } \\
\text { assimilação gradual e de mudanças } \\
\text { em tarefas de trabalho, apoio dos } \\
\text { colegas de setor. }\end{array}$ \\
\hline $\begin{array}{l}\text { Johnsson } \\
\text { et al. }{ }^{23} \\
\text { (Suécia) }\end{array}$ & $\begin{array}{l}\text { Identificar fatores } \\
\text { que contribuem } \\
\text { para um retorno } \\
\text { bem sucedido } \\
\text { ao mercado de } \\
\text { trabalho após o } \\
\text { tratamento para } \\
\text { câncer de mama a } \\
\text { partir da própria } \\
\text { perspectiva das } \\
\text { mulheres. } \\
\end{array}$ & $\begin{array}{l}16 \text { mulheres } \\
\text { sobreviventes do } \\
\text { câncer de mama com } \\
\text { idade de } 44 \text { a } 58 \text { anos }\end{array}$ & $\begin{array}{l}\text { Entrevistas } \\
\text { narrativas }\end{array}$ & $\begin{array}{l}\text { Análise de } \\
\text { conteúdo descrito } \\
\text { nos modelos de } \\
\text { Mishler e Creswell. }\end{array}$ & $\begin{array}{l}\text { Barreiras: capacidade reduzida e } \\
\text { falta de apoio social no ambiente } \\
\text { de trabalho. } \\
\text { Facilitadores: a importância } \\
\text { do apoio social no ambiente de } \\
\text { trabalho no processo de RT. }\end{array}$ \\
\hline $\begin{array}{l}\text { Nilsson } \\
\text { et al. }{ }^{24} \\
\text { (Suécia) }\end{array}$ & $\begin{array}{l}\text { Adquirir } \\
\text { conhecimento } \\
\text { sobre a experiência } \\
\text { do RT de mulheres } \\
\text { durante e após } \\
\text { a trajetória do } \\
\text { câncer de mama e } \\
\text { o encontro delas } \\
\text { com as partes } \\
\text { interessadas. }\end{array}$ & $\begin{array}{l}23 \text { mulheres } \\
\text { tratadas para câncer } \\
\text { de mama com idade } \\
\text { de } 20 \text { a } 63 \text { anos. }\end{array}$ & Grupos focais & $\begin{array}{l}\text { Análise de } \\
\text { conteúdo }\end{array}$ & $\begin{array}{l}\text { Barreiras: melhores ajustes quanto } \\
\text { à alteração de tarefas, tempo, } \\
\text { local ou horas de trabalho. Mais } \\
\text { informações sobre a doença/ } \\
\text { tratamento e os benefícios } \\
\text { conferidos a estas em razão do CM. } \\
\text { Facilitadores: a importância de } \\
\text { atitudes positivas de amigos, } \\
\text { colegas e profissionais de saúde } \\
\text { quanto ao processo de RT. }\end{array}$ \\
\hline $\begin{array}{c}\text { Tiedtke } \\
\text { et al. }{ }^{25} \\
\text { (Bélgica) }\end{array}$ & $\begin{array}{l}\text { Avaliar as } \\
\text { experiências } \\
\text { das mulheres de } \\
\text { serem afastadas do } \\
\text { trabalho por causa } \\
\text { do câncer de mama. }\end{array}$ & $\begin{array}{l}22 \text { mulheres de } 41 \text { a } \\
55 \text { anos submetidas a } \\
\text { cirurgia do câncer de } \\
\text { mama em } 2006 \text { e que } \\
\text { estavam empregadas } \\
\text { ou não estavam } \\
\text { incapacitadas no } \\
\text { momento. }\end{array}$ & $\begin{array}{l}\text { Entrevistas } \\
\text { narrativas }\end{array}$ & $\begin{array}{l}\text { Teoria } \\
\text { fundamentada nos } \\
\text { dados de campo } \\
\text { (grounded theory). }\end{array}$ & $\begin{array}{l}\text { Barreiras: a doença como uma } \\
\text { perda irreparável e falta esperança } \\
\text { no futuro; e falta de compreensão } \\
\text { médica sobre a forma como as } \\
\text { pacientes experimentam a doença } \\
\text { e incapacidade. } \\
\text { Facilitadores: uma preparação } \\
\text { física ou mental, acreditando no } \\
\text { RT como um passo em direção à } \\
\text { recuperação da vida normal; e a } \\
\text { busca de informações, a testagem de } \\
\text { habilidades e fazer planos concretos } \\
\text { para voltar ao trabalho. }\end{array}$ \\
\hline
\end{tabular}

(Continua) 
Quadro 1 Continuação...

\begin{tabular}{|c|c|c|c|c|c|}
\hline $\begin{array}{c}\text { Autores } \\
\text { (país) }\end{array}$ & Objetivo do estudo & Participantes & Coleta de dados & Método de análise & $\begin{array}{c}\text { Barreiras e Facilitadores do } \\
\text { RT após CM }\end{array}$ \\
\hline $\begin{array}{c}\text { Tamminga } \\
\text { et al. }{ }^{9} \\
\text { (Holanda) }\end{array}$ & $\begin{array}{l}\text { Identificar: fatores } \\
\text { experimentados } \\
\text { como barreiras } \\
\text { e facilitadores } \\
\text { do processo de } \\
\text { retorno ao trabalho } \\
\text { (RTW); quais fatores } \\
\text { foram importantes } \\
\text { durante a formação } \\
\text { e pós RTW; e as } \\
\text { possíveis soluções a } \\
\text { RTW problemas. }\end{array}$ & $\begin{array}{l}12 \text { mulheres } \\
\text { sobreviventes do } \\
\text { câncer de mama } \\
\text { com idade média de } \\
42 \text { anos. }\end{array}$ & $\begin{array}{l}\text { Entrevistas } \\
\text { narrativas }\end{array}$ & \begin{tabular}{|l} 
As entrevistas foram \\
tematicamente \\
analisadas usando \\
MAXQDA, software \\
para análise de \\
dados qualitativos e \\
usada a Classificação \\
Internacional de \\
Funcionalidade, \\
Incapacidade e \\
Saúde(CIF) como um \\
quadro conceitual.
\end{tabular} & $\begin{array}{l}\text { Barreiras: desconfiança do } \\
\text { empregador, incentivos a não } \\
\text { voltar a trabalhar, elevada carga } \\
\text { de trabalho física, altas demandas } \\
\text { mentais, falta de apoio de colegas, } \\
\text { supervisores, empregadores } \\
\text { e/ou médicos ocupacionais, } \\
\text { recuperação lenta ou insuficiente } \\
\text { ao longo do tempo. } \\
\text { Facilitadores: apoio e } \\
\text { relacionamento com a família, } \\
\text { amigos, assistentes pessoais, } \\
\text { profissionais de saúde e outros } \\
\text { sobreviventes de câncer de } \\
\text { mama são importantes porque } \\
\text { eles fornecem apoio prático e } \\
\text { encorajamento e permitem a } \\
\text { discussão sobre RT. }\end{array}$ \\
\hline $\begin{array}{l}\text { Tiedtke } \\
\text { et al. }{ }^{26} \\
\text { (Bélgica) }\end{array}$ & $\begin{array}{l}\text { Elucidar as } \\
\text { experiências de } \\
\text { pacientes com } \\
\text { câncer de mama } \\
\text { ao considerarem o } \\
\text { RT e compreender } \\
\text { melhor se os } \\
\text { afastamentos } \\
\text { laborais no } \\
\text { contexto belga } \\
\text { estão relacionados } \\
\text { às reações de seu } \\
\text { ambiente social. }\end{array}$ & $\begin{array}{l}22 \text { participantes } \\
\text { com idade média } \\
\text { de } 46 \text { anos foram } \\
\text { e entrevistadas } \\
\text { entre maio de } 2008 \\
\text { e agosto de } 2009 \\
\text { em seu ambiente } \\
\text { pessoal. }\end{array}$ & $\begin{array}{l}\text { Entrevistas } \\
\text { narrativas }\end{array}$ & $\begin{array}{l}\text { Teoria } \\
\text { fundamentada nos } \\
\text { dados de campo } \\
\text { (grounded theory). }\end{array}$ & $\begin{array}{l}\text { Barreiras: preocupação com a } \\
\text { recuperação e medo da perda } \\
\text { de capacidade para o trabalho; } \\
\text { e expectativas e medo sobre a } \\
\text { aceitação dos colegas no RT. } \\
\text { Facilitadores: necessidades } \\
\text { financeiras e apoio do ambiente } \\
\text { de trabalho. }\end{array}$ \\
\hline $\begin{array}{l}\text { Nilsson } \\
\text { et al. }^{27} \\
\text { (Suécia) }\end{array}$ & $\begin{array}{l}\text { Visa elucidar como } \\
\text { as mulheres com } \\
\text { câncer de mama } \\
\text { refletem e agem } \\
\text { sobre questões } \\
\text { relacionadas com o } \\
\text { trabalho. }\end{array}$ & $\begin{array}{l}23 \text { mulheres entre } \\
20 \text { e } 63 \text { anos } \\
\text { diagnosticadas pela } \\
\text { primeira vez com } \\
\text { câncer de mama que } \\
\text { realizaram cirurgia } \\
\text { nos últimos } 3 \text { a } 13 \\
\text { meses }\end{array}$ & Grupos focais & $\begin{array}{l}\text { Análise de } \\
\text { temáticas como } \\
\text { descrito por Brown } \\
\text { e Clarke. }\end{array}$ & $\begin{array}{l}\text { Barreiras: efeitos colaterais } \\
\text { do tratamento influenciaram } \\
\text { a capacidade de trabalho das } \\
\text { mulheres no RT. } \\
\text { Facilitadores: os ajustes do } \\
\text { trabalho de acordo com as } \\
\text { necessidades da trabalhadora; e o } \\
\text { apoio social e a necessidade de RT } \\
\text { por razões econômicas. }\end{array}$ \\
\hline $\begin{array}{l}\text { Tiedtke } \\
\text { et al. } \\
\text { (Bélgica) }\end{array}$ & $\begin{array}{l}\text { Adquirir uma } \\
\text { compreensão } \\
\text { profunda de como } \\
\text { as funcionárias } \\
\text { flamengas } \\
\text { experimentam } \\
\text { seu RT depois do } \\
\text { câncer de mama } \\
\text { e com o apoio do } \\
\text { local de trabalho }\end{array}$ & $\begin{array}{l}14 \text { mulheres (com } \\
\text { idades entre } 42 \\
\text { e } 45 \text { anos, com } \\
\text { idade média de } \\
48 \text { no momento } \\
\text { da cirurgia) que } \\
\text { sofreram câncer de } \\
\text { mama e retornaram } \\
\text { ao trabalho. }\end{array}$ & $\begin{array}{l}\text { Entrevistas } \\
\text { narrativas }\end{array}$ & $\begin{array}{l}\text { Teoria } \\
\text { fundamentada nos } \\
\text { dados de campo } \\
\text { (grounded theory). }\end{array}$ & $\begin{array}{l}\text { Barreiras: problemas físicos, tais } \\
\text { como: falta de energia, grave } \\
\text { cansaço e sentir-se como "velhas" } \\
\text { foram mencionados; e problemas } \\
\text { mentais, especialmente: menor } \\
\text { concentração, como resultado da } \\
\text { quimioterapia. } \\
\text { Facilitadores: diálogo sobre } \\
\text { limitações laborais como facilitador } \\
\text { do gerenciamento do trabalho; e } \\
\text { necessidade de apoio informal e do } \\
\text { suporte ambiental para reduzirem } \\
\text { os sentimentos de vulnerabilidade. }\end{array}$ \\
\hline
\end{tabular}


Quadro 2 Análise da qualidade dos estudos selecionados sobre retorno ao trabalho de mulheres com câncer de mama, segundo Critical Appraisal Skills Programme $(C A S P)^{15}$

\begin{tabular}{|c|c|c|c|c|c|c|c|c|c|}
\hline & {$[1]$} & [2] & [3] & [4] & [5] & [6] & [7] & {$[8]$} & [9] \\
\hline \multicolumn{10}{|l|}{ 1) Houve uma declaração clara dos objetivos da pesquisa? } \\
\hline a) Qual o objetivo da pesquisa? & $\mathbf{x}$ & $\mathbf{x}$ & $\mathbf{x}$ & $\mathrm{x}$ & $\mathbf{x}$ & $\mathbf{x}$ & $\mathbf{x}$ & $\mathbf{x}$ & $\mathbf{x}$ \\
\hline b) Por que é importante? & $\mathbf{x}$ & $\mathbf{x}$ & $\mathbf{x}$ & $\mathrm{x}$ & $\mathrm{x}$ & $\mathbf{x}$ & $\mathbf{x}$ & $\mathbf{x}$ & $\mathbf{x}$ \\
\hline c) É relevante? & $\mathbf{x}$ & $\mathbf{x}$ & $\mathbf{x}$ & $\mathrm{x}$ & $\mathrm{x}$ & $\mathbf{x}$ & $\mathbf{x}$ & $\mathbf{x}$ & $\mathbf{x}$ \\
\hline \multicolumn{10}{|l|}{\begin{tabular}{|l|} 
2. É um método qualitativo apropriado? \\
\end{tabular}} \\
\hline $\begin{array}{l}\text { a) Se a pesquisa procura interpretar ou iluminar as ações } \\
\text { e/ou as experiências subjetivas dos participantes da } \\
\text { pesquisa. }\end{array}$ & $\mathbf{x}$ & $\mathbf{x}$ & $\mathbf{x}$ & $\mathbf{x}$ & $\mathbf{x}$ & $\mathbf{x}$ & $\mathbf{x}$ & $\mathbf{x}$ & $\mathbf{x}$ \\
\hline \multicolumn{10}{|l|}{$\begin{array}{l}\text { 3. O desenho da pesquisa é apropriado para enquadrar os } \\
\text { objetivos da pesquisa? }\end{array}$} \\
\hline $\begin{array}{l}\text { a) O pesquisador justificou o desenho da pesquisa } \\
\text { (por exemplo, ele discutiu como ele decidiu por qual } \\
\text { método utilizar?) }\end{array}$ & & & $\mathbf{x}$ & $\mathbf{x}$ & & $\mathbf{x}$ & $\mathrm{x}$ & $\mathbf{x}$ & $\mathbf{x}$ \\
\hline \multicolumn{10}{|l|}{$\begin{array}{l}\text { 4. A estratégia de recrutamento é apropriada para o } \\
\text { encaminhamento da pesquisa? }\end{array}$} \\
\hline $\begin{array}{l}\text { a) O pesquisador explicou como os participantes foram } \\
\text { selecionados? }\end{array}$ & $\mathbf{x}$ & $\mathbf{x}$ & $\mathbf{x}$ & $\mathbf{x}$ & $\mathbf{x}$ & $\mathbf{x}$ & $\mathbf{x}$ & $\mathbf{x}$ & $\mathrm{x}$ \\
\hline $\begin{array}{l}\text { b) Eles explicaram porque os participantes selecionados } \\
\text { seriam os mais apropriados para dar acesso ao tipo de } \\
\text { conhecimento procurado pelo estudo? }\end{array}$ & & & $\mathbf{x}$ & $\mathrm{x}$ & & $\mathbf{x}$ & $\mathbf{x}$ & $\mathbf{x}$ & $\mathbf{x}$ \\
\hline $\begin{array}{l}\text { c) Se há alguma discussão acerca do recrutamento } \\
\text { (por exemplo, por que algumas pessoas optaram por } \\
\text { não fazer parte?) }\end{array}$ & & & & $\mathrm{x}$ & & $\mathrm{x}$ & & $\mathbf{x}$ & $\mathbf{x}$ \\
\hline \multicolumn{10}{|l|}{$\begin{array}{l}\text { 5. Os dados coletados são uma forma de } \\
\text { encaminhamento para a questão da pesquisa? }\end{array}$} \\
\hline a) Se o cenário da coleta de dados foi justificado. & $\mathbf{x}$ & $\mathbf{x}$ & & $\mathbf{x}$ & $\mathbf{x}$ & $\mathrm{x}$ & $\mathbf{x}$ & $\mathbf{x}$ & $\mathbf{x}$ \\
\hline $\begin{array}{l}\text { b) Se está claro como os dados formam coletados (por } \\
\text { exemplo: grupos focais; entrevista semiestruturada etc.). }\end{array}$ & $\mathbf{x}$ & $\mathbf{x}$ & $\mathbf{x}$ & $\mathbf{x}$ & $\mathbf{x}$ & $\mathbf{x}$ & $\mathbf{x}$ & $\mathbf{x}$ & $\mathbf{x}$ \\
\hline c) Se o pesquisador justificou a escollha dos métodos. & & $x$ & $\mathbf{x}$ & $\mathbf{x}$ & $\mathbf{x}$ & $\mathbf{x}$ & $\mathbf{x}$ & $\mathbf{x}$ & $\mathbf{x}$ \\
\hline $\begin{array}{l}\text { d) Se o pesquisador fez o detalhamento dos métodos } \\
\text { (por exemplo, sobre o método da entrevista, há alguma } \\
\text { indicação de como as entrevistas foram conduzidas, ou } \\
\text { eles usaram um roteiro?). }\end{array}$ & $\mathbf{x}$ & $\mathbf{x}$ & $\mathbf{x}$ & $\mathrm{x}$ & $\mathbf{x}$ & $\mathbf{x}$ & $\mathbf{x}$ & $\mathbf{x}$ & $\mathbf{x}$ \\
\hline \multicolumn{10}{|l|}{$\begin{array}{l}\text { e) Se os métodos foram modificados durante a pesquisa. } \\
\text { Se sim, o pesquisador explicou como e por quê? }\end{array}$} \\
\hline $\begin{array}{l}\text { f) Se a forma dos dados está clara (por exemplo: gravação } \\
\text { de áudio; material filmado; notas etc). }\end{array}$ & $\mathbf{x}$ & $\mathbf{x}$ & $\mathbf{x}$ & $\mathbf{x}$ & $\mathbf{x}$ & $\mathbf{x}$ & $\mathbf{x}$ & $\mathbf{x}$ & $\mathbf{x}$ \\
\hline g) Se o pesquisador discutiu a saturação de dados. & $\mathbf{x}$ & & & & & & & & $\mathrm{x}$ \\
\hline \multicolumn{10}{|l|}{$\begin{array}{l}\text { 6. A relação do pesquisador com os participantes foi } \\
\text { adequadamente considerada? }\end{array}$} \\
\hline $\begin{array}{l}\text { a1) Se o pesquisador examinou criticamente o seu próprio } \\
\text { papel, viés e influencia durante: a formulação das questões } \\
\text { de estudo. }\end{array}$ & & & $\mathbf{x}$ & & $\mathbf{x}$ & $\mathbf{x}$ & $\mathbf{x}$ & $\mathbf{x}$ & $\mathbf{x}$ \\
\hline $\begin{array}{l}\text { a2) Se o pesquisador examinou criticamente o seu próprio } \\
\text { papel, viés e influencia durante: coleta de dados, seleção } \\
\text { da amostra e escolha do local. }\end{array}$ & $\mathrm{x}$ & & & $\mathbf{x}$ & $\mathbf{x}$ & $\mathbf{x}$ & $\mathbf{x}$ & $\mathbf{x}$ & $\mathbf{x}$ \\
\hline $\begin{array}{l}\text { b) Como o pesquisador responde a eventos durante o } \\
\text { estudo e se considerou as implicações de quaisquer } \\
\text { alterações no projeto de pesquisa? }\end{array}$ & & & & & & & & & $\mathbf{x}$ \\
\hline
\end{tabular}

(Continua) 
Quadro 2 Continuação...

\begin{tabular}{|c|c|c|c|c|c|c|c|c|c|}
\hline & [1] & [2] & [3] & [4] & [5] & [6] & [7] & [8] & [9] \\
\hline \multicolumn{10}{|l|}{ 7. Objetivos éticos foram considerados? } \\
\hline $\begin{array}{l}\text { a) Se tem dados suficientes da maneira como a pesquisa } \\
\text { foi explicada aos participantes e leitores em relação à } \\
\text { manutenção dos padrões éticos. }\end{array}$ & $\mathbf{x}$ & & $\mathbf{x}$ & $\mathbf{x}$ & $\mathbf{x}$ & & $\mathbf{x}$ & $\mathbf{x}$ & $\mathbf{x}$ \\
\hline $\begin{array}{l}\text { b) Se o pesquisador discutiu as questões levantadas pelo } \\
\text { estudo (por exemplo, questões sobre informação do termo } \\
\text { de consentimento e confidencialidade ou como ele lidou } \\
\text { com os efeitos do estudo sobre os participantes durante e } \\
\text { depois do estudo). }\end{array}$ & & & $\mathbf{x}$ & & $\mathbf{x}$ & $\mathbf{x}$ & $\mathbf{x}$ & $\mathbf{x}$ & $\mathbf{x}$ \\
\hline c) Se há aprovação do comitê de ética. & $\mathbf{x}$ & & $\mathbf{x}$ & $\mathbf{x}$ & $\mathbf{x}$ & $\mathbf{x}$ & $\mathbf{x}$ & $\mathbf{x}$ & $\mathbf{x}$ \\
\hline \multicolumn{10}{|l|}{ 8. A análise de dados foi suficientemente rigorosa? } \\
\hline a) Se há uma profunda descrição do processo de análise. & & $\mathrm{x}$ & $\mathbf{x}$ & $\mathrm{x}$ & $x$ & $x$ & $x$ & $\mathbf{x}$ & \\
\hline $\begin{array}{l}\text { b) Se a analise temática é usada. Se sim, ficou claro como as } \\
\text { categorias/temas foram derivadas dos dados? }\end{array}$ & $\mathbf{x}$ & $\mathbf{x}$ & $\mathbf{x}$ & $\mathbf{x}$ & $\mathbf{x}$ & $\mathbf{x}$ & $\mathbf{x}$ & $\mathbf{x}$ & $\mathbf{x}$ \\
\hline $\begin{array}{l}\text { c) Se o pesquisador explicou como a apresentação dos } \\
\text { dados foi selecionada da amostra original para demonstrar } \\
\text { o processo de análise. }\end{array}$ & & & $\mathbf{x}$ & $\mathbf{x}$ & $x$ & $\mathbf{x}$ & $\mathbf{x}$ & $\mathbf{x}$ & \\
\hline $\begin{array}{l}\text { d) Se dados foram suficientemente apresentados para dar } \\
\text { suporte aos achados. }\end{array}$ & & $x$ & $\mathbf{x}$ & $\mathbf{x}$ & $\mathbf{x}$ & $\mathbf{x}$ & $\mathbf{x}$ & $\mathbf{x}$ & $\mathbf{x}$ \\
\hline $\begin{array}{l}\text { e) Até que ponto os dados contraditórios são levados em } \\
\text { conta? }\end{array}$ & & & $\mathbf{x}$ & $\mathbf{x}$ & & $\mathbf{x}$ & & $\mathbf{x}$ & $\mathbf{x}$ \\
\hline $\begin{array}{l}\text { f) Se o pesquisador examinou criticamente o seu próprio } \\
\text { papel, potenciais vieses e influência durante a análise e } \\
\text { seleção de dados apresentados. }\end{array}$ & $\mathbf{x}$ & & & & $\mathbf{x}$ & $\mathbf{x}$ & $\mathbf{x}$ & $\mathbf{x}$ & \\
\hline \multicolumn{10}{|l|}{ 9. Há uma clara demonstração de resultados? } \\
\hline a) Se os achados estão explícitos. & $x$ & $x$ & $x$ & $x$ & $x$ & $x$ & $x$ & $\mathbf{x}$ & $x$ \\
\hline $\begin{array}{l}\text { b) Se há uma adequada discussão das evidencias favoráveis } \\
\text { ou contrárias aos argumentos do pesquisador. }\end{array}$ & $\mathbf{x}$ & $\mathbf{x}$ & $\mathbf{x}$ & $\mathbf{x}$ & $x$ & $\mathbf{x}$ & $\mathbf{x}$ & $\mathbf{x}$ & $\mathbf{x}$ \\
\hline $\begin{array}{l}\text { c) Se o pesquisador discutiu a credibilidade dos achados } \\
\text { (por exemplo, triangulação, validação interna, mais de um } \\
\text { analisador). }\end{array}$ & & & & $\mathbf{x}$ & $\mathbf{x}$ & $\mathbf{x}$ & $\mathbf{x}$ & $\mathbf{x}$ & $\mathbf{x}$ \\
\hline $\begin{array}{l}\text { d) Se os achados foram discutidos em relação à questão } \\
\text { original da pesquisa. }\end{array}$ & $\mathbf{x}$ & $\mathbf{x}$ & $\mathbf{x}$ & $\mathbf{x}$ & $\mathbf{x}$ & $\mathbf{x}$ & $\mathbf{x}$ & $\mathbf{x}$ & $\mathbf{x}$ \\
\hline \multicolumn{10}{|l|}{ 10. Qual a validade desse estudo? } \\
\hline $\begin{array}{l}\text { a) Se o pesquisador discute a contribuição do estudo para } \\
\text { o conhecimento e entendimento existentes (por exemplo, } \\
\text { eles consideraram os achados em relação a pratica e política } \\
\text { correntes, ou a pesquisa de base literária relevante). }\end{array}$ & $\mathbf{x}$ & $\mathbf{x}$ & $\mathbf{x}$ & $\mathbf{x}$ & $x$ & $\mathbf{x}$ & $\mathbf{x}$ & $x$ & $\mathbf{x}$ \\
\hline $\begin{array}{l}\text { b) Se eles identificam novas áreas em que a pesquisa é } \\
\text { necessária. }\end{array}$ & $\mathbf{x}$ & $\mathbf{x}$ & $\mathbf{x}$ & $\mathbf{x}$ & $\mathbf{x}$ & $\mathbf{x}$ & $\mathbf{x}$ & $\mathbf{x}$ & $\mathbf{x}$ \\
\hline $\begin{array}{l}\text { c) Se os pesquisadores discutiram se e como os } \\
\text { dados podem ser transferidos para outra população } \\
\text { considerando que outras formas de pesquisa podem ser } \\
\text { utilizadas. }\end{array}$ & & & & & & $\mathbf{x}$ & $\mathbf{x}$ & $\mathbf{x}$ & $\mathbf{x}$ \\
\hline
\end{tabular}

Nota: [1] Maunsell et al. ${ }^{21} ;[2]$ Kennedy et al. ${ }^{22} ;[3]$ Johnsson et al. ${ }^{23} ;[4]$ Nilsson et al. ${ }^{24} ;[5]$ Tiedtke et al. ${ }^{25} ;[6]$ Tammiga et al. ${ }^{9} ;$ [7] Tiedtke et al..$^{26}$; [8] Nilsson et al. ${ }^{27} ;\left[9 \mid\right.$ Tiedtke et al. ${ }^{28}$ 
Quadro 3 Avaliação do rigor metodológico dos estudos selecionados sobre retorno ao trabalho de mulheres com câncer de mama, segundo Consolidated Criteria for Reporting Qualitative Research (COREQ) ${ }^{16}$

\begin{tabular}{|c|c|c|c|c|c|c|c|c|c|}
\hline & [1] & [2] & {$[3]$} & [4] & [5] & [6] & [7] & {$[8]$} & [9] \\
\hline \multicolumn{10}{|l|}{ Domínio 1: equipe de pesquisa $\&$ reflexividade } \\
\hline 1. Entrevistador/facilitador & $\mathbf{x}$ & $\mathrm{x}$ & $\mathrm{x}$ & $\mathrm{x}$ & $\mathrm{x}$ & $\mathrm{x}$ & $\mathbf{x}$ & $\mathrm{x}$ & $\mathbf{x}$ \\
\hline 2. Credenciais & $\mathrm{x}$ & & $\mathrm{x}$ & $\mathrm{x}$ & $\mathbf{x}$ & $\mathrm{x}$ & $\mathrm{x}$ & $\mathrm{x}$ & $\mathrm{x}$ \\
\hline 3. Ocupação & $\mathbf{x}$ & & $\mathbf{x}$ & $\mathbf{x}$ & $\mathbf{x}$ & $\mathbf{x}$ & $\mathbf{x}$ & $\mathrm{x}$ & $\mathbf{x}$ \\
\hline 4. Gênero & $\mathbf{x}$ & & & & & $\mathrm{x}$ & $\mathrm{x}$ & & $\mathrm{x}$ \\
\hline 5. Experiência/treinamento & & & $\mathbf{x}$ & $\mathrm{x}$ & $\mathbf{x}$ & $\mathrm{x}$ & & $\mathrm{x}$ & \\
\hline 6. Relacionamento com os participantes & & & & & $\mathbf{x}$ & & $\mathrm{x}$ & & $\mathbf{x}$ \\
\hline 7. Conhecimento dos participantes sobre a intervenção & $\mathbf{x}$ & & $\mathbf{x}$ & $\mathbf{x}$ & $\mathbf{x}$ & $\mathbf{x}$ & $\mathrm{x}$ & $\mathrm{x}$ & $\mathbf{x}$ \\
\hline 8. Características da intervenção & $\mathrm{x}$ & $\mathrm{x}$ & $\mathrm{x}$ & $\mathrm{x}$ & $\mathbf{x}$ & $\mathrm{x}$ & $\mathrm{x}$ & $\mathrm{x}$ & $\mathrm{x}$ \\
\hline \multicolumn{10}{|l|}{ Domínio 2: desenho de estudo } \\
\hline \multicolumn{10}{|l|}{ Quadro Teórico } \\
\hline 9. Metodologia de orientação & $\mathbf{x}$ & $\mathbf{x}$ & $\mathbf{x}$ & $\mathbf{x}$ & $\mathbf{x}$ & $\mathbf{x}$ & $\mathbf{x}$ & $\mathbf{x}$ & $\mathbf{x}$ \\
\hline \multicolumn{10}{|l|}{ Seleção de Participantes } \\
\hline 10. Amostragem & $\mathrm{x}$ & $\mathbf{x}$ & $\mathbf{x}$ & $\mathbf{x}$ & $\mathbf{x}$ & $\mathbf{x}$ & $\mathbf{x}$ & $\mathbf{x}$ & $\mathrm{x}$ \\
\hline 11. Método de abordagem & $\mathrm{x}$ & $\mathbf{x}$ & $\mathrm{x}$ & $\mathrm{x}$ & $\mathrm{x}$ & $\mathbf{x}$ & $\mathrm{x}$ & $\mathrm{x}$ & $\mathbf{x}$ \\
\hline 12. Tamanho da amostra & $\mathbf{x}$ & $\mathbf{x}$ & $\mathbf{x}$ & $\mathrm{x}$ & $\mathbf{x}$ & $\mathrm{x}$ & $\mathrm{x}$ & $\mathrm{x}$ & $\mathbf{x}$ \\
\hline 13. Não participação & $\mathrm{x}$ & & & $\mathrm{x}$ & $\mathbf{x}$ & $\mathrm{x}$ & $\mathrm{x}$ & $\mathrm{x}$ & $\mathrm{x}$ \\
\hline \multicolumn{10}{|l|}{ Configuração } \\
\hline 14. Configuração da coleta de dados & $\mathrm{x}$ & $\mathbf{x}$ & $\mathrm{x}$ & $\mathbf{x}$ & $\mathrm{x}$ & $\mathrm{x}$ & $\mathrm{x}$ & $\mathrm{x}$ & $\mathbf{x}$ \\
\hline 15. Presença de não participantes & $\mathbf{x}$ & & & $\mathbf{x}$ & $\mathbf{x}$ & & $\mathbf{x}$ & & \\
\hline 16. Descrição da amostra & $\mathrm{x}$ & $\mathbf{x}$ & $\mathrm{x}$ & $\mathrm{x}$ & $\mathrm{x}$ & $\mathbf{x}$ & $\mathrm{x}$ & $\mathrm{x}$ & $\mathrm{x}$ \\
\hline \multicolumn{10}{|l|}{ A coleta de dados } \\
\hline 17. Guia de entrevista & $\mathrm{x}$ & $\mathbf{x}$ & $\mathrm{x}$ & $\mathrm{x}$ & $\mathrm{x}$ & $\mathbf{x}$ & $\mathrm{x}$ & $\mathrm{x}$ & $\mathbf{x}$ \\
\hline \multicolumn{10}{|l|}{ 18. Entrevistas repetidas } \\
\hline 19. Gravações áudio/visuais & $\mathrm{x}$ & $\mathrm{x}$ & $\mathrm{x}$ & $\mathrm{x}$ & $\mathrm{x}$ & $\mathrm{x}$ & $\mathrm{x}$ & $\mathrm{x}$ & $\mathrm{x}$ \\
\hline \multicolumn{10}{|l|}{ 20. Notas de campo } \\
\hline 21. Duração & & $\mathbf{x}$ & $\mathrm{x}$ & $\mathbf{x}$ & $x$ & $\mathbf{x}$ & $\mathrm{x}$ & $\mathrm{x}$ & $\mathbf{x}$ \\
\hline 22. Saturação & & & & & & $\mathbf{x}$ & $\mathbf{x}$ & $\mathrm{x}$ & $\mathbf{x}$ \\
\hline \multicolumn{10}{|l|}{ 23. Transcrições refeitas } \\
\hline \multicolumn{10}{|l|}{\begin{tabular}{|l|} 
Domínio 3: análise dos achados \\
\end{tabular}} \\
\hline \multicolumn{10}{|l|}{ A análise de dados } \\
\hline 24. Número de dados coletados & $\mathrm{x}$ & $\mathrm{x}$ & $\mathrm{x}$ & $\mathrm{x}$ & $x$ & $\mathrm{x}$ & $\mathrm{x}$ & $x$ & $\mathrm{x}$ \\
\hline 25. Descrição dos dados coletados & $\mathrm{x}$ & $\mathrm{x}$ & $\mathbf{x}$ & $\mathrm{x}$ & $\mathbf{x}$ & $\mathbf{x}$ & $\mathrm{x}$ & $\mathrm{x}$ & $\mathrm{x}$ \\
\hline 26. Derivação dos temas & $\mathrm{x}$ & $\mathrm{x}$ & $\mathrm{x}$ & $\mathrm{x}$ & $\mathrm{x}$ & $\mathrm{x}$ & $\mathrm{x}$ & $\mathrm{x}$ & $\mathrm{x}$ \\
\hline 27. Software & & & & $\mathbf{x}$ & $\mathrm{x}$ & $\mathbf{x}$ & $\mathrm{x}$ & $\mathrm{x}$ & $\mathbf{x}$ \\
\hline 28. Checagem dos participantes & & & & & $\mathbf{x}$ & $\mathbf{x}$ & $\mathbf{x}$ & & $\mathrm{x}$ \\
\hline \multicolumn{10}{|l|}{ Devolutiva } \\
\hline 29. Resultados apresentados & $\mathbf{x}$ & $\mathrm{x}$ & $\mathbf{x}$ & $\mathrm{x}$ & $\mathbf{x}$ & $\mathbf{x}$ & $\mathrm{x}$ & $\mathbf{x}$ & $\mathrm{x}$ \\
\hline 30. Dados e resultados consistentes & $\mathrm{x}$ & $\mathrm{x}$ & $\mathrm{x}$ & $\mathrm{x}$ & $\mathbf{x}$ & $\mathbf{x}$ & $\mathrm{x}$ & $\mathrm{x}$ & $\mathbf{x}$ \\
\hline 31.Clareza dos temas maiores & $\mathrm{x}$ & $\mathrm{x}$ & $\mathrm{x}$ & $\mathrm{x}$ & $\mathbf{x}$ & $\mathbf{x}$ & $\mathrm{x}$ & $\mathrm{x}$ & $\mathbf{x}$ \\
\hline 32. Clareza dos temas menores & $\mathrm{x}$ & $\mathrm{x}$ & $\mathrm{x}$ & $\mathrm{x}$ & $\mathrm{x}$ & $\mathrm{x}$ & $\mathrm{x}$ & $\mathrm{x}$ & $\mathrm{x}$ \\
\hline
\end{tabular}

Nota: [1] Maunsell et al. ${ }^{21} ;$ [2] Kennedy et al. ${ }^{22}$; [3] Johnsson et al. ${ }^{23}$; [4] Nilsson et al. ${ }^{24}$; [5] Tiedtke et al. ${ }^{25}$; [6] Tammiga et al. ${ }^{9} ;$ [7] Tiedtke et al. ${ }^{26}$; $[8]$ Nilsson et al. ${ }^{27} ;[9]$ Tiedtke et al. ${ }^{28}$

Fonte: Adaptado de Banning? 
As publicações que compuseram esta metassíntese referem-se apenas a países do hemisfério norte: Bélgica $^{25,26,28}$; Canadá21; Suécia ${ }^{23,24,27}$; Holanda ${ }^{9}$; e Reino Unido ${ }^{22}$, o que aponta a necessidade de ampliar os investimentos em pesquisas sobre essa temática em países com realidades econômicas, previdenciárias e sociais diferentes das referenciadas.

Foram observadas diferenças nas legislações dos países em que os estudos foram realizados. Países onde não existem legislações que obriguem os empregadores a orientar a retomada das atividades laborais, as sobreviventes do CM apresentam RT pobre, sobretudo em razão da falta de apoio dos empregadores ${ }^{25,26,28}$. Nestas circunstâncias, os trabalhos evidenciaram que as percepções das mulheres sobre o desejo de voltar a trabalhar estiveram associadas a sentimentos de dependência, vulnerabilidade e incertezas. Por outro lado, nos países onde a legislação implica tanto o empregador quanto o empregado(a) na responsabilidade pelo processo de RT, há um incremento de ajustes no ambiente de trabalho e nas tarefas para trabalhadores(as) que têm necessidades de readaptação funcional ${ }^{9,21-24,28}$.

Verifica-se que as consequências biopsicossociais, do estar ou não na condição de trabalho, influenciaram no RT prematuro ou tardio de mulheres após o CM e que as legislações e os modelos de sistemas de saúde dos países em que elas estão inseridas interferiram diretamente em suas percepções de como os contextos institucionais as auxiliam ou não na retomada da atividade laborais ${ }^{9,21-26,28}$.

Com base nos conceitos de primeira ordem que surgiram de cada estudo empírico selecionado, foi possível produzir seis conceitos de segunda ordem, que emergiram da comparação desses estudos, os quais serão apresentados por categoria, e a síntese (terceira ordem), que será discutida (Quadro 4).

Quadro 4 Conceitos de primeira ordem, de segunda ordem e a síntese (terceira ordem)

\begin{tabular}{|c|c|c|c|}
\hline $\begin{array}{l}\text { Autores } \\
\text { (país) }\end{array}$ & $\begin{array}{l}\text { Conceitos de primeira ordem } \\
\text { (classificados de acordo com os conceitos de } \\
\text { segunda ordem que dele se originou) }\end{array}$ & $\begin{array}{l}\text { Conceitos de segunda ordem } \\
\text { conforme os mundos da vida }\end{array}$ & $\begin{array}{c}\text { Síntese } \\
\text { dos estudos }\end{array}$ \\
\hline $\begin{array}{l}\text { Maunsell } \\
\text { et al. } 21 \\
\text { (Canadá) }\end{array}$ & $\begin{array}{l}\text { A. Lidar com o diagnóstico da doença e as repercussões no } \\
\text { contexto de trabalho em relação aos colegas e supervisores } \\
\text { quando do câncer; } \\
\text { B. Apreensões sobre o RT quanto à capacidade de trabalho } \\
\text { e gerenciamento de tarefas por conta da diminuição da } \\
\text { produtividade em função da doença; } \\
\text { C. Medo de alterações indesejadas das condições de } \\
\text { trabalho após o tratamento, como perda de cargos ou } \\
\text { redução de salários; } \\
\text { D. Suporte do profissional de saúde para tratar do RT; e } \\
\text { E. Mudanças de atitudes em relação ao trabalho. }\end{array}$ & \multirow{4}{*}{$\begin{array}{l}\text { A. O diagnóstico do câncer } \\
\text { de mama e como as mulheres } \\
\text { lidam com os efeitos da doença } \\
\text { e do afastamento do ambiente } \\
\text { de trabalho (corporalidade }{ }^{18} \text { ). } \\
\text { B. As expectativas do RT } \\
\text { frente à capacidade para o } \\
\text { trabalho e o gerenciamento } \\
\text { das tarefas (corporalidade e } \\
\text { relacionalidade }{ }^{18} \text { ). }\end{array}$} & \multirow[t]{4}{*}{$\begin{array}{l}\text { O retorno ao trabalho é } \\
\text { um processo significado } \\
\text { pelas mulheres na } \\
\text { reflexão e interconexão } \\
\text { dos seus diferentes } \\
\text { mundos da vida. }\end{array}$} \\
\hline $\begin{array}{l}\text { Kennedy } \\
\text { et al. } \\
\text { (Reino Unido) }\end{array}$ & $\begin{array}{l}\text { A. Expectativas quanto a capacidade de trabalho, ajustes no } \\
\text { trabalho, efeitos do câncer e do tratamento no RT; } \\
\text { B. A questão financeira como fator que influencia na } \\
\text { decisão de voltar a trabalhar; } \\
\text { C. Reflexões sobre retornar ou não ao trabalho após o } \\
\text { câncer e a duração do afastamento em razão da doença; e } \\
\text { D. Suporte do profissional de saúde, apoio dos colegas e } \\
\text { empregadores. }\end{array}$ & & \\
\hline $\begin{array}{l}\text { Johnsson } \\
\text { et al. }{ }^{23} \\
\text { (Suécia) }\end{array}$ & $\begin{array}{l}\text { A. Flexibilização de horários e de cargas de trabalho; } \\
\text { B. Necessidades financeiras, medo de não serem capazes de } \\
\text { retornar ou serem marginalizadas no mercado de trabalho; } \\
\text { C. Importância do apoio social no local de trabalho; } \\
\text { D. A mudança do significado do trabalho; e } \\
\text { E. Sentimentos pessoais sobre pertencer ao mercado } \\
\text { de trabalho. }\end{array}$ & & \\
\hline $\begin{array}{l}\text { Nilsson } \\
\text { et al. } 24 \\
\text { (Suécia) }\end{array}$ & $\begin{array}{l}\text { A. Ajustes e mudanças em relação ao trabalho; } \\
\text { B. (In)flexibilidade das regras de benefícios de } \\
\text { afastamentos; } \\
\text { C. A troca de informações e de experiências pessoais de } \\
\text { amigos e colegas de trabalho facilitando o RT; } \\
\text { D. Preocupações da família quanto ao RT após a doença; e } \\
\text { E. Suporte do profissional de saúde no RT e o apoio } \\
\text { adequado dos colegas de trabalho. }\end{array}$ & & \\
\hline
\end{tabular}


Quadro 4 Continuação...

\begin{tabular}{|c|c|c|c|}
\hline $\begin{array}{l}\text { Autores } \\
\text { (país) }\end{array}$ & $\begin{array}{l}\text { Conceitos de primeira ordem } \\
\text { (classificados de acordo com os conceitos de } \\
\text { segunda ordem que dele se originou) }\end{array}$ & $\begin{array}{l}\text { Conceitos de segunda ordem } \\
\text { conforme os mundos da vida }\end{array}$ & $\begin{array}{c}\text { Síntese } \\
\text { dos estudos }\end{array}$ \\
\hline $\begin{array}{l}\text { Tiedtke } \\
\text { et al. } 25 \\
\text { (Bélgica) }\end{array}$ & $\begin{array}{l}\text { A. A experiência de ser afastada do trabalho em razão do } \\
\text { câncer como uma interrupção, com perdas irreparáveis, } \\
\text { desespero e sem esperança para o futuro; } \\
\text { B. Sentimento de incapacidade frente ao ritmo acelerado } \\
\text { de trabalho; } \\
\text { C. A reintegração no trabalho sem complicações médicas e } \\
\text { o temor de recaídas; } \\
\text { D. Sentir-se indesejável no trabalho; e } \\
\text { E. Com a doença, a vida assume um novo significado e em } \\
\text { uma nova atitude em relação ao trabalho. }\end{array}$ & \multirow[t]{5}{*}{$\begin{array}{l}\text { F. Mudança do significado } \\
\text { do trabalho após a } \\
\text { doença. (Espacialidade e } \\
\text { temporalidade }{ }^{18} \text { ). }\end{array}$} & \\
\hline $\begin{array}{l}\text { Tamminga } \\
\text { et al. }{ }^{9} \\
\text { (Holanda) }\end{array}$ & $\begin{array}{l}\text { A. Barreiras no RT: efeitos colaterais físicos ou } \\
\text { psicológicos, temperamento, personalidade e atitudes } \\
\text { sociais; } \\
\text { B. Preocupações financeiras; } \\
\text { C. O apoio do supervisor e colegas como fatores que } \\
\text { influenciaram no RT; } \\
\text { D. Orientações de profissionais de saúde e informações } \\
\text { para os colegas devem ser melhoradas; e } \\
\text { E. A importância do trabalho. }\end{array}$ & & \\
\hline $\begin{array}{l}\text { Tiedtke } \\
\text { et al. } 26 \\
\text { (Bélgica) }\end{array}$ & $\begin{array}{l}\text { A. Transição entre estar doente e voltar a trabalhar; } \\
\text { B. Expectativas frente aos empregadores e colegas quanto } \\
\text { à capacidade laboral, produtividade e gerenciamento de } \\
\text { tarefas e aceitação no ambiente de trabalho; } \\
\text { C. Insegurança financeira; } \\
\text { D. Medo de recidivas: questionamentos sobre a } \\
\text { recuperação } \times \text { RT; e } \\
\text { E. Necessidade de suporte dos profissionais de saúde } \\
\text { quanto ao RT. }\end{array}$ & & \\
\hline $\begin{array}{l}\text { Nilsson } \\
\text { et al. } 27 \\
\text { (Suécia) }\end{array}$ & $\begin{array}{l}\text { A. Efeitos colaterais do tratamento e a influência na } \\
\text { capacidade no trabalho; } \\
\text { B. Questionamentos sobre revelar ou esconder o câncer; } \\
\text { C. Ajustar ou não as horas e tarefas de trabalho e a vida de } \\
\text { acordo com as próprias necessidades; } \\
\text { D. Razões econômicas influenciando o RT; } \\
\text { E. A segurança oferecida por um ambiente de trabalho } \\
\text { amistoso, sendo considerada como um aspecto importante } \\
\text { no RT; } \\
\text { F. Orgulho e alegria ao conseguir voltar a trabalhar; e } \\
\text { E. Mudança de prioridades. }\end{array}$ & & \\
\hline $\begin{array}{l}\text { Tiedtke } \\
\text { et al. } 28 \\
\text { (Bélgica) }\end{array}$ & $\begin{array}{l}\text { A. Sentimento de vulnerabilidade física e mental e } \\
\text { confrontamento com desafios no RT; } \\
\text { B. Diferentes pontos de vista sobre a sua capacidade para } \\
\text { o trabalho relacionado: (i) à sua saúde; (ii) às tarefas que } \\
\text { tinham de realizar; e (iii) às suas relações no trabalho } \\
\text { (colegas e compensações); } \\
\text { C. Demissões e o estigma da doença aumentaram a } \\
\text { vulnerabilidade; } \\
\text { D. Sensação de ter se modificado após a doença, adaptação } \\
\text { a uma nova vida, insegurança frente ao futuro quanto às } \\
\text { recidivas; } \\
\text { E. Necessidade do apoio (in)formal e do suporte ambiental } \\
\text { para reduzirem os sentimentos de vulnerabilidade; } \\
\text { F. A vivência do câncer pelos colegas/ empregador os } \\
\text { levaram a serem ainda mais apoiadores e compreensivos; e } \\
\text { G. A percepção de que apoio do local de trabalho pode } \\
\text { variar de acordo com a política organizacional. }\end{array}$ & & \\
\hline
\end{tabular}


O Diagnóstico do câncer de mama e como as mulheres lidam com os efeitos da doença e do afastamento do ambiente de trabalho

Os estudos apresentaram a saída das mulheres das atividades laborais apenas por demandas pessoais em razão da doença, não foram claramente abordados os aspectos relacionados às condições gerais do ambiente de trabalho, que também pudessem justificar este afastamento ${ }^{9,21-25,27}$. Nos artigos, a saída do trabalho foi percebida como uma fase de interrupção e perdas, mediada pela incapacidade transitória e pela forma abrupta como foi afastada ${ }^{9,21,22,24,25,27}$, permeada ainda por mudanças físicas como perda do peito, queda de cabelo etc. e por entraves de ordem mental com destaque para tristeza e falta de concentração dentre outros fatores ${ }^{21,23,25,26,28}$.

Tais eventos produziram uma ressignificação do trabalho no RT em diferentes sentidos ${ }^{9,21-27}$. Algumas mulheres perceberam o trabalho como fonte de bem-estar, como possibilidade de normalizar sua vida, suas emoções e expectativas positivas de superação da doença ${ }^{21,22,24,25}$. Outras sentiam que o CM havia mudado a percepção que tinham do trabalho, estando menos interessadas na vida profissional, tornando a vida social e familiar uma prioridade maior do que antes do diagnóstico ${ }^{9,22,25}$. Observa-se, portanto, que o diagnóstico, os efeitos da doença e o afastamento do trabalho em si não podem ser tomados como barreiras absolutas, mas como elementos de mudança de perspectiva em relação a várias dimensões da vida, inclusive o trabalho, podendo configurar-se ora como facilitadores ora como barreiras do processo de RT.

Expectativas do retorno ao trabalho frente à capacidade para o trabalho e o gerenciamento das tarefas

As apreensões frente ao empregador ou colegas sobre a capacidade de execução de tarefas, a própria percepção de que precisavam de um tempo para se readaptarem e o receio de induzirem a erro os empregadores ao pensarem que elas tinham se recuperado completamente foram elementos descritos na fase inicial de $\mathrm{RT}^{9,21,22,25-28}$.

Algumas mulheres ao tentarem transparecer certa normalidade na capacidade para o trabalho, acabavam por se exceder no $\mathrm{RT}^{21-23,26}$. Outras desejavam o RT, mas sentiam medo de não conseguirem gerenciar bem suas tarefas ${ }^{25,27,28}$. Nenhum dos estudos que compõem esta metassíntese apresentou quais tarefas passaram a ser realizadas pelas trabalhadoras no $\mathrm{RT}^{9,21-28}$. Boa parte das pesquisas relatou apenas as alterações indesejadas nas tarefas ${ }^{9,21-23}$, as dificuldades com readaptações em tarefas complexas ou novas ${ }^{9,26-28}$ e que tarefas de trabalho não adaptadas para cada indivíduo dificultavam o processo de $\mathrm{RT}^{28}$.
Outrossim, as necessidades pessoais impostas pela doença passaram a demandar negociações com empregadores quanto a flexibilização de horários, assimilação gradual das atividades e necessidade de mudanças nas tarefas de trabalho. Nesse processo, ora os supervisores produziam ajustes automaticamente $^{24}$, ora foram solicitados pelas próprias trabalhadoras $9,21,22,27$. Este aspecto negocial deve ser analisado tanto como facilitador quanto como barreira ao processo de reabilitação, uma vez que os estudos realizados em países onde há um incentivo ao RT, este processo é facilitado pelos próprios gesto$\mathrm{res}^{22,24}$. Já em países onde não se encontravam claras as regras de readaptação, tais ajustes apresentavam tensões entre as partes interessadas ${ }^{9,27}$.

\section{Questões financeiras}

Os estudos revelaram que as narrativas das mulheres com "retorno tardio" diferiram das narrativas das mulheres que conseguiram voltar mais rapidamente ao trabalho. Isso porque trabalhadoras que tiveram um RT tardio relatavam a necessidade de priorizar a recuperação pós-doença ${ }^{26,27}$; já aquelas que conseguiam voltar mais cedo, tinham o desafio de manterem seu lugar no mercado de trabalho ${ }^{9,21-23}$. Contudo, não ficou claro o que explicava ambas decisões. Suspeita-se que um dos elementos pode ser de ordem financeira.

Mulheres que receberam algum tipo de benefício relataram ter sorte de não ter que voltar a trabalhar imediatamente ${ }^{22}$. Por outro lado, insegurança e desespero surgiram em trabalhadoras que enfrentavam dificuldades financeiras durante a doença, o que as levavam, por vezes, a sofrerem em silêncio pela necessidade de RT mesmo sem se sentirem aptas para assumir suas atividades ${ }^{25,26,28}$.

Aquelas que não possuíam empregos estáveis relataram que era difícil se ausentar do trabalho por vários meses e não serem substituídas. Elas acreditavam também que o CM implicaria em dificuldades para encontrar um novo emprego, pois o histórico de câncer levantaria dúvidas sobre a sua capacidade de trabalho ${ }^{21-23,27}$.

Percebe-se assim que as crenças, atitudes e influências de cada trabalhadora em relação ao RT estão atreladas aos contextos e contingências em que vivem sendo também influenciadas pelas políticas de reabilitação em que são inseridas e pela forma como percebem e reinterpretam seu mundo do trabalho ou a falta dele.

\section{Medo de recorrência da doença}

Além do diagnóstico e tratamento do CM terem sido concebidos como fatores perturbadores do curso 
normal da vida ${ }^{9,21,25,26}$, seja pela dificuldade de manter o segredo sobre a enfermidade para os colegas de trabalho, seja pela necessidade de ter que conciliar o tratamentos com a carga horária de trabalho ${ }^{9,21,24,27}$, o medo da recidiva consistiu num fenômeno que perpassou todos os estudos e também se apresentou como uma barreira ao RT, pois havia nas mulheres um receio de retornarem precocemente sem estarem completamente "curadas" por considerarem que, apesar de terem alta, a doença poderia a qualquer momento "atacá-las" novamente $\mathrm{e}^{9,21-28}$.

Assim, a baixa imunidade e o medo de infecções influenciaram na decisão por trabalhar em tempo integral ou parcial quando do $\mathrm{RT}^{22,27}$. Além disso, dificuldades para dormir, fadigas, linfedemas, funções cognitivas afetadas foram associadas à perda da capacidade de trabalho ${ }^{9,24,27}$. Tais problemas significaram barreiras para o RT, pois para algumas mulheres era difícil aceitar que não teriam condições de trabalhar tanto quanto antes e pensar em mudar de emprego/atividade era concebido por muitas como uma situação ameaçadora por demandar a aquisição de novas habilidades físicas e psíquicas ${ }^{21,22}$.

Suporte dos profissionais de saúde, apoio da família e dos colegas no ambiente de trabalho

O suporte da família e amigos foi relatado como importante no processo de reabilitação $\mathrm{O}^{24,26-28}$ uma vez que, além do RT, as mulheres tinham que gerir as demandas domésticas ${ }^{9}$. A influência dos depoimentos de amigos sobre possíveis problemas cognitivos após o CM e a falta de apoio dos colegas de trabalho, nas situações em que o empregador foi resistente ao processo de readaptação, foram preponderantes nos casos em que o RT não transcorreu da forma que a trabalhadora imaginava ${ }^{24,26 .}$

Assim, declarações ofensivas, olhares constrangedores, perguntas irritantes ou um silêncio embaraçoso foram algumas das experiências negativas relatadas quando da retomada das atividades laborais após o $\mathrm{CM}^{21,24}$. Ficou evidenciada, em boa parte dos artigos, a satisfação das mulheres quando apoiadas por colegas e gestores. Esta experiência era mais intensa quando elas recebiam palavras de incentivo enquanto ainda estavam fora do trabalho ${ }^{9,22-24}$.

Os estudos destacaram o papel dos profissionais de saúde no $\mathrm{RT}^{9,21,22,24,26,28}$. Em alguns casos tidos como solidários e encorajadores ${ }^{26,24,27}$. Mas encontrou-se também relatos de atitudes negativas, como pressionar as trabalhadoras a retornar ao trabalho quando elas não se sentiam ainda prontas. Nesses casos, essas mulheres encaravam estes comportamentos como rudes e produtores de descrédito e desconfiança quanto ao real estado de saúde da trabalhadora ${ }^{9,21,22,24}$.
Algumas pesquisas indicaram que trabalhadoras que discutiam questões pertinentes ao trabalho com seus médicos estruturavam melhor um plano de $\mathrm{RT}^{9,21,22,24,26,28}$. Tais aspectos relacionados ao apoio social puderam ser interpretados como facilitadores do RT, uma vez que ao serem encorajadas à reabilitação pelas equipes de saúde, amigos e familiares, havia uma diminuição da ansiedade dessas trabalhadoras quanto ao processo de retomada da vida profissional ${ }^{9,24}$.

\section{Mudança do significado do trabalho após a doença}

Os estudos evidenciaram que o CM mudou a percepção das trabalhadoras quanto ao conteúdo e às condições de trabalho ${ }^{9,21-28}$. Modificações no conteúdo das tarefas, redução nos ganhos, perdas de cargos anteriormente ocupados foram mudanças indesejadas após o câncer ${ }^{21,23,25}$. Algumas mulheres viram essas modificações como atos de discriminação, uma vez que não tiveram um diálogo e/ou apoio adequado no $\mathrm{RT}^{21}$, já outras consideraram um desdobramento natural da perda de suas capacidades produtivas ${ }^{21,23}$.

Assim, o fato de ter tido um CM mudou atitudes, prioridades, sentimentos e relacionamentos no trabalho após a doença ${ }^{9,21-28}$. Para algumas mulheres, o trabalho deixou de ser um fardo quando passaram a trabalhar menos horas por $\mathrm{dia}^{21,27}$ e reavaliaram suas preferências ocupacionais sobre no que e para quem elas queriam trabalhar ${ }^{9,23}$. Já outras expressaram o sentido de trabalho como uma "distração" frente à doença ${ }^{9,22,25,27}$ e um sinal de que haviam recuperado a saúde, pois pertencer ao mercado de trabalho representaria um "retorno à vida"9,22-24,26.

\section{Discussão}

Nessa metassíntese, tomamos os significados interpretados dos estudos originais como expressões dos mundos da vida, como algo que foi submetido a um processo reflexivo, colocado em relevo e posteriormente traduzido pelos autores deste estudo.

Apoiando-se num importante pressuposto das teorias compreensivas de que "a experiência não é separada do participante, de modo que o contexto também precisa ser articulado"18, e, com base nos conceitos de segunda ordem anteriormente mencionados, nos aportes teóricos do RT e na noção de contexto de Munhall ${ }^{18}$, apresentamos a síntese deste estudo.

O Retorno ao trabalho como um processo significado pelas mulheres na reflexão e interconexão dos seus diferentes mundos da vida

O material reunido nos estudos descreve o RT num contexto dinâmico, que não se limita à reação 
destas mulheres frente aos obstáculos e facilitadores da reabilitação, mas à construção e reconstrução dos seus mundos da vida após o $\mathrm{CM}^{29}$. É nos diferentes mundos da vida dessas trabalhadoras, interpretados e descritos nos artigos, que é possível falar sobre as etapas da reabilitação e sobre seus novos significados reinterpretados.

Corporalidade: $\mathrm{O}$ conceito de segunda ordem: $o$ diagnóstico do câncer de mama e como as mulheres lidam com os efeitos da doença e do afastamento do ambiente de trabalho forneceu elementos para pensar nesse aspecto do mundo da vida, pois as histórias pessoais apresentadas nos estudos deflagraram o impacto que a doença causou na vida dessas mulheres e quais julgamentos e perplexidades elas imprimiram nos colegas de trabalho e na sociedade. Acerca dessa significação inicial, Sontag ${ }^{30}$ ressalta que:

Nada é mais punitivo do que atribuir um significado a uma doença quando esse significado é invariavelmente moralista. Qualquer moléstia importante cuja causa é obscura e cujo tratamento é ineficaz tende a ser sobrecarregada de significação onde a própria doença se torna uma metáfora. E a doença (assim enriquecida de significados) é projetada no mundo. (p. 76)

Assim, o período de off work $^{11}$, em razão da doença, é significado através dos contextos situados e das contingências do dia a dia que cada trabalhadora vive e que são marcados pelas suas histórias de vida pessoais ${ }^{18}$, podendo fazer com que elas vivenciem esse momento fora do ambiente de trabalho como um período de instabilidade que oscila entre a renovação e o desespero no contexto das relações interpessoais, em que cada mulher lida com os sintomas da doença e externaliza aos grupos sociais onde se encontra inserida de uma maneira muito particular ${ }^{31}$.

Os estudos evidenciaram que, apesar de existirem fatores pessoais, organizacionais e políticos de saúde que influenciam no $\mathrm{RT}^{32}$, a reabilitação ainda permanece centrada em iniciativas individuais da própria trabalhadora enferma e numa baixa corresponsabilização dos demais atores envolvidos no processo de reabilitação $0^{9,21-28}$. Assim, a descoberta da doença refletiu num processo dinâmico de busca pessoal por equilíbrio à medida que o tratamento avançava e as trabalhadoras concebiam novos significados para o momento que estavam passando ${ }^{4,26}$.

"Compreende-se assim que a doença, especialmente a doença crônica, é precisamente o tipo de experiência em que as estruturas da vida cotidiana e as formas de conhecimento que as sustentam se rompem" (p. 43) ${ }^{33}$. Para essas mulheres, que experimentaram o CM, há uma nova inteligência corporal que necessita ser significada após as transformações físicas e psíquicas provocadas pela doença. É através dessa reconstrução da unidade mente/corpo que se torna possível compreender tal experiência, uma vez que significado e experiência não podem existir isoladamente ${ }^{18}$.

Este mundo da vida também pôde ser contemplado pelo conceito de segunda ordem: as expectativas do RT frente à capacidade para o trabalho e o gerenciamento das tarefas. Isso porque os estudos relatam diferentes expectativas sobre o voltar a trabalhar, tanto durante as semanas que antecedem essa reentrada ${ }^{11}$ quanto na fase inicial do RT.

\begin{abstract}
Uma possibilidade fundamental na vida da pessoa estigmatizada é a colaboração que presta aos normais no sentido de atuar como se a sua qualidade diferencial manifesta não tivesse importância nem merecesse atenção especial. Entretanto, quando a diferença não está imediatamente aparente e não se tem dela um conhecimento prévio (ou, pelo menos, ela não sabe que os outros a conhecem), quando, na verdade, ela é uma pessoa desacreditável, e não desacreditada, nesse momento é que aparece a segunda possibilidade fundamental em sua vida. A questão que se coloca não é a da manipulação da tensão gerada durante os contatos sociais e, sim, da manipulação de informação sobre o seu defeito. Exibi-lo ou ocultá-lo; contá-lo ou não contá-lo; revelá-lo ou escondê-lo; mentir ou não mentir; e, em cada caso, para quem, como, quando e onde. (p. 51) $)^{34}$
\end{abstract}

Concordamos com as colocações de Goffman ${ }^{34}$, tendo em vista que há uma "borda" de imprevisibilidade dessas mulheres no RT, pois muitas sequer conhecem suas capacidades produtivas durante esta retomada da vida ocupacional ${ }^{26-28}$. Já outras trabalhadoras sabem que não conseguem mais se colocar na ativa como antes, mas preferem aparentar uma normalidade pelo medo de represálias ou demissões ${ }^{9,21-23}$.

Ajustes na carga horária de trabalho, permissões de saídas para consultas e exames e o gerenciamento de tarefas foram pontuados como características propiciadoras do RT após o $\mathrm{CM}^{9,22-24}$. Já as elevadas cargas físicas e/ou psíquicas no trabalho, além do baixo apoio nos ambientes de trabalho (colegas, empregadores, médicos ocupacionais), foram identificados como barreiras para o processo de reabilitação ${ }^{9,23}$. Tais elementos reiteram os conhecimentos existentes em trabalhos anteriores sobre os facilitadores e obstáculos do RT após $\mathrm{CM}^{4,7,8}$ e confirmam que o processo de RT é lento, desafiador e depende de múltiplos fatores, pois não ocorre através de uma sobreposição de importância entre estes, e, por ser individualizado, requer a identificação de quais fatores atuam como facilitadores e/ou barreiras para um RT sustentado ${ }^{32}$.

Espacialidade: Tanto o conceito de segunda ordem suporte dos profissionais de saúde, apoio da família e dos colegas no ambiente de trabalho quanto o conceito mudança do significado do trabalho após a doença fundamentaram este aspecto da síntese. 
Isso porque realizada a reentrada no ambiente de trabalho, o desafio agora é manter (maintenance) esta trabalhadora em atividade e centrada nas metas a serem alcançadas no trabalho diário, considerando inclusive a possibilidade de progressão na carreira $^{11,12}$.

Essas trabalhadoras têm a necessidade de discutir suas limitações nos espaços onde ocorrem suas readaptações funcionais (situação que possibilita maior gerenciamento de seu trabalho). Políticas de reintegração, que visem ambientes de trabalho saudáveis, valorizem a trabalhadora com incapacidades enquanto sujeito e mantenham sua autonomia como indivíduos são propiciadores de maior efetividade ao RT sustentado ${ }^{32}$, sendo que tais transformações somente são possíveis quando interligadas às trocas intersubjetivas que estas mulheres realizam nos diferentes ambientes onde estão situadas.

No entanto, Munhall ${ }^{35}$ nos alerta que a percepção da experiência é o que importa, não o que na realidade pode parecer contrário ou mais "verdadeiro". Se o ambiente de trabalho é visto como perigoso pela trabalhadora (seja pela sua baixa imunidade e medo de recidivas ou necessidade de novos ajustes nas tarefas a serem executadas), ainda quando "de fato" não haja perigo mensurável por outrem, torna-se necessário compreender que, na realidade dessa mulher, há perigo e isso deve ser trabalhado em parceria com colegas e gestores quando da manutenção dessa mulher no local de trabalho.

Ao compreender os diferentes espaços em que estas trabalhadoras se encontram e os significados que estes assumem nestas experiências, nota-se que o CM possibilita a estas mulheres contemplar diversos momentos de sua vida durante o período do adoecer. A ruptura de suas biografias permite, simultaneamente, relembrar o passado vivido e contemplar um futuro almejado ao mesmo tempo em que buscam redescobrir quem são após, por exemplo, a perda do peito ${ }^{18}$. Tais experiências permitem que o trabalho possa ter, para algumas mulheres, um significado secundário após a sua recuperação, desejando, sim, voltar à atividade, mas conduzindo-a de forma diferente, acrescentando novas perspectivas e planos para sua existência ${ }^{7}$.

Relacionalidade: a relacionalidade foi identificada no conceito de segunda ordem: as expectativas do RT frente à capacidade para o trabalho e o gerenciamento das tarefas, uma vez que algumas trabalhadoras se sentiam como "um fardo" para os colegas ou "um peso" para os supervisores ou que "esbarraram em uma parede de tijolos" pela falta de conselhos úteis durante a reabilitação ${ }^{25,27}$, aspectos estes que também são tratados em outros trabalhos da literatura investigada ${ }^{3,8,31}$.
Todas as pessoas vivem num mundo de encontros sociais que as envolvem, ou em contato face a face, ou em contato mediado com outros participantes. Em cada um desses contatos a pessoa tende a desempenhar o que às vezes é chamado de linha - quer dizer, um padrão de atos verbais e não verbais com o qual ela expressa sua opinião sobre a situação, e através disto sua avaliação sobre os participantes, especialmente ela própria. Não importa que a pessoa pretenda assumir uma linha ou não, ela sempre o fará na prática. Os outros participantes pressuporão que ela assumiu uma posição mais ou menos voluntariamente, de forma que se ela quiser ser capaz de lidar com a resposta deles a ela, ela precisará levar em consideração a impressão que eles possivelmente formaram sobre ela. (pág. 13) ${ }^{36}$

Assim, a experiência de RT pode ser contemplada de uma forma mais positiva ou mais negativa a depender do grau em que o ambiente de trabalho é capaz de reconhecer a vulnerabilidade da trabalhadora e tratar esta condição com o apoio adequado ou não ${ }^{25,26,23}$.

Outro conceito de segunda ordem que evidenciou a relacionalidade foi o suporte dos profissionais de saúde, apoio da família e dos colegas no ambiente de trabalho. Para as mulheres, o apoio de colegas e supervisores propicia encorajamento e faz a sobrevivente do CM sentir que voltou a um lugar seguro e familiar ${ }^{9,22,26,28}$. Em contrapartida, a carência de suporte do empregador e colegas de trabalho foi indicada como resultado da falta de informações por parte das organizações sobre políticas de reabilitação de trabalhadores(as) com adoecimentos crônicos, uma vez que os gestores também sentiram que precisavam de subsídios para lidar com as demandas destas mulheres ${ }^{9}$. Isso demonstra como os empregadores podem achar difícil encontrar o equilíbrio entre dar apoio exacerbado ou paternalista e permitir que a trabalhadora retorne à normalidade com o suporte necessário ${ }^{9,21-24,27}$. Em tais situações, o RT ao trabalho só foi concretizado quando a trabalhadora possuía um suporte de familiares, amigos e/ou profissionais de saúde $\mathrm{de}^{9,21,25-27}$.

Arman e Rehnsfeldt ${ }^{37}$ apontam que a presença simultânea de benefícios e danos demonstra um processo de polarização das perspectivas de vida que são emanadas da experiência do CM. Assim, as descrições das mulheres formam um campo dialético (de tensão) entre a vida e a morte no qual são criados novos níveis de consciência e sabedoria. Nesse sentido, as transformações da perspectiva da vida no RT após a experiência do CM são parte de uma trama complexa e, neste processo, é importante perceber que todos os atores sociais: colegas, gestores, trabalhadora etc. estão interligados e implicados.

Neves, Nunes e Magalhães ${ }^{12}$, ao estudar as interações entre atores no RT após afastamento por transtorno mental, destacam que normas socioculturais, 
conflitos socioeconômicos e políticos e as relações de interesse e poder produzem impactos na experiência de RT das pessoas que sofrem de transtornos mentais. Estas ponderações também são válidas no RT de sobreviventes do CM uma vez que a sociedade deve ser informada sobre a importância do trabalho para as mulheres e que elas são capazes de retornar para suas atividades laborativas durante ou após o tratamento desde que recebam o apoio que precisam $^{9,23,24,26}$.

O apoio social deve, portanto, propiciar uma maior sensibilização de visões renovadas e aprofundadas do significado da vida. Um fator decisivo pode ser se a sobrevivente obtém o suporte de um companheiro, um amigo ou até mesmo um colega de trabalho. Esse compartilhamento de experiências, emoções e pensamentos com outras pessoas pode "salvar" sujeitos que estão passando por mudanças significativas na vida ${ }^{37}$. Lima e $\operatorname{Trad}^{38}$, ao estudarem a dinâmica presente na circulação de doentes e terapeutas de uma clínica da dor, destacam a importância de múltiplas vozes e relações dialógicas e interdisciplinares do cotidiano de sujeitos em busca de tratamentos.

Tais colocações também são pertinentes na atuação do profissional de saúde que cuida da reabilitação de trabalhadoras com CM uma vez que os estudos que compõem essa metassíntese indicaram que o suporte da família, amigos, colegas de trabalho, profissionais de saúde fornece apoio prático, encorajamento e abre a discussão sobre o RT sustentado $^{32}$, permitindo que estas mulheres não se sintam sozinhas durante essa jornada ${ }^{9,21-28}$. Assim, nas narrativas de RT também existem muitas "vozes": da trabalhadora, da família, de amigos, colegas, gestores, profissionais de saúde etc. e é através dessa "espiral de intervenções" ${ }^{38}$, construída por meio da intersubjetividade, que se torna possível a reabilitação.

Temporalidade: Entende-se temporalidade não como o tempo cronológico, mas como o tempo da consciência, no qual passado, presente e futuro se fundem em três presentes: presente do passado, presente do presente e presente do futuro, todos mediados pelas contingências individuais ${ }^{18}$. Este componente do mundo da vida foi significado pelos conceitos de segunda ordem: questões financeiras e o medo de recorrência da doença.

Estas categorias também trazem implicações inerentes à fase inicial de $\mathrm{RT}^{11}$, apontando que estas trabalhadoras muitas vezes vivenciam circunstâncias de vida adversas (pois algumas são provedoras do lar ou de parte significativa da renda familiar) e realidades do cotidiano que as impulsionam a querer voltar o quanto antes ao trabalho ainda que tenham medo de recidivas da doença. Por outro lado, o tempo é o tempo que estamos vivendo ${ }^{18}$. Nesses termos, a percepção da passagem do tempo pode variar bastante, conforme a experiência ${ }^{18,39}$.

Outro conceito de segunda ordem que está presente neste componente contextual é a mudança do significado do trabalho após a doença. Ao interpretarem o seu próprio mundo e explicarem o processo da doença, as sobreviventes do CM compreendem as suas próprias experiências. E, apesar destas mulheres por vezes terem conseguido, ao longo do tempo, se readaptarem ao contexto do trabalho após o $\mathrm{CM}$ e terem alcançado condições para seguir o curso de suas carreiras (Advancement) ${ }^{11,12}$, a importância do trabalho mudou e perdeu parte do seu significado para muitas delas.

Percebe-se que a temporalidade envolta no RT se constrói e reconstrói, pois corresponde ao tempo da consciência mediada pelas experiências passadas, pelas vividas no agora e pelas projetadas ou antecipadas para o futuro. Então, é no processo chamado de RT que esse tempo é significado. Ora tido como lento ou insuficiente ${ }^{9,26,28}$, ora percebido como curto e desagradável, após o qual a vida cotidiana seria retomada ${ }^{21,23,24}$. Dessa forma, tal contemplação não pode ser vista como um caminho único e acabado, uma vez que o crítico do tempo é a própria história ${ }^{18}$.

\section{Considerações finais}

Apesar de ter sido incluída a SciELO (onde são indexados estudos da América Latina e Caribe), não foram localizadas nessa biblioteca eletrônica pesquisas qualitativas que tratassem dos significados do RT após a experiência do CM, o que limita a comparabilidade e transferibilidade desses achados para cenários como os da América Latina e evidencia a necessidade de ampliar os investimentos em pesquisa sobre o RT entre sobreviventes de câncer de mama em outros contextos a fim de aferir se os achados apresentados noutros lugares guardam alguma correspondência com apresentados neste estudo.

Além disso, apesar dos artigos analisados informarem o interesse na compreensão da experiência de RT de sobreviventes do CM, nenhuma publicação apresentou um conceito de experiência com fundamentação teórica de base fenomenológica.

Nesta metassíntese, alguns autores ${ }^{9,21,22,24,27}$ adotaram uma abordagem mais descritiva do conceito de experiência relatando situações e fatores do trabalho que viabilizam ou não o RT das sobreviventes do câncer de mama. Outros ${ }^{23,25,26,28}$, apesar de apresentarem realidades do cotidiano destas mulheres, não adotaram uma perspectiva clara de quais aportes teóricos embasaram a compreensão dessas experiências 
de reconstrução do mundo da vida de mulheres em RT após o câncer.

Contudo, os métodos desenvolvidos nos artigos forneceram subsídios aos seus resultados, havendo uma correspondência entre os dados registrados e as interpretações trazidas em cada estudo. Até porque os estudos investigados aqui fizeram uma aproximação das mulheres que vivenciaram o RT após o $\mathrm{CM}$, adotando a perspectiva de que a palavra "experiência” pode ser contemplada de diferentes formas. Contudo, ficou claro que os autores exploraram a premissa de que "as respostas aos problemas criados pela doença constituem-se socialmente e remetem diretamente a um mundo compartilhado de práticas, crenças e valores" ${ }^{40}$.

Nenhum dos trabalhos apontou quais mudanças estruturais ocorreram nos ambientes após o RT das sobreviventes do CM. Além dos fatores psicossociais (identificados ora como barreiras, ora como facilitadores), não foram detalhados outros fatores de risco influenciadores do RT. Sugere-se que pesquisas posteriores explorem melhor as alterações estruturais dos ambientes de trabalho onde se situam essas trabalhadoras em RT, descrevendo inclusive aspectos organizacionais e outros fatores de risco (níveis de ruído, gases, vibrações, poeiras etc.) aos quais essas sobreviventes do CM são expostas, o que permitirá compreender melhor que condições de trabalho são facilitadoras do processo de reintegração.
Ao adotar a corporeidade, espacialidade, relacionalidade e temporalidade para a analisar a reabilitação de trabalhadoras após o $\mathrm{CM}$, os estudos apontaram o RT como um processo complexo que é experienciado desde o diagnóstico, perpassa o tratamento da doença e a saída da mulher do ambiente de trabalho até que surjam os anseios e expectativas da retomada da vida laboral, sobretudo no que tange à capacidade produtiva e ao gerenciamento de tarefas e cuidados com a saúde.

Destacam-se, como componentes desta síntese, a influência das questões financeiras, o medo de recidivas, bem como as mudanças de significado que o trabalho sofre depois da doença. Os trabalhos apontaram que as principais dificuldades das sobreviventes do CM no RT estão relacionadas à falta de políticas de reabilitação mais eficazes no sentido de orientar colegas e gestores acerca das demandas e limitações dessas trabalhadoras. Como alternativas, os estudos reforçam a necessidade de valorização das relações intersubjetivas das partes interessadas no processo de reabilitação laboral.

A síntese também evidenciou o CM como uma doença crônica de longa duração que demanda intervenções nos ambientes laborais e implica no aprimoramento do suporte às trabalhadoras quando do RT, devendo ser apoiado por todas as partes interessadas a fim de permitir que cada mulher, de maneira singular, porém compartilhada com colegas e gestores, consiga se manter em situação de trabalho e em condições de prevenir a incapacidade prolongada.

\section{Contribuições de autoria}

Costa, JB contribuiu na concepção, levantamento, análise, interpretação dos dados e redação do manuscrito. Lima, MAG e Neves, RB contribuíram no delineamento e na redação e revisão crítica do manuscrito. Todos os autores se responsabilizam publicamente pelo trabalho e seu conteúdo.

\section{Referências}

1. Jemal A, Vineis P, Bray F, Torre L, Forman D, editores. The cancer atlas [Internet]. 2a ed. Atlanta: American Cancer Society; 2014 [citado em 3 jun 2020]. Disponível em: www.cancer.org/canceratlas.

2. Instituto Nacional de Câncer José Alencar Gomes da Silva. Estimativa 2018: incidência de câncer no Brasil. Rio de Janeiro; 2017.

3. Verbeek J, Spelten E. Work. In: Feuerstein M, editor. Handbook of cancer survivorship. New York: Springer International Publishing; 2007. p. 381-96.

4. Sandberg JC, Strom C, Arcury TA. Strategies used by breast cancer survivors to address work-related limitations during and after treatment. Womens Health Issues. 2014;24(2):197-204.
5. Mehnert A. Employment and work-related issues in cancer survivors. Crit Rev Oncol Hematol. 2011;77(2):109-30.

6. Pransky G, Gatchel R, Linton SJ, Loisel P. Improving return to work research. J Occup Rehabil. 2005;15(4):453-7.

7. Banning M. Employment and breast cancer: a meta-ethnography. Eur J Cancer Care. 2011;20(6):708-19.

8. Wells M, Williams B, Firnigl D, Lang H, Coyle J, Kroll T, et al. Supporting "work-related goals" rather than "return to work" after cancer? A systematic review and meta-synthesis of 25 qualitative studies. Psychooncology. 2013;22(6):1208-19. 
9. Tamminga SJ, de Boer AGEM, Verbeek JH, FringsDresen MHW. Breast cancer survivors' views of factors that influence the return-to-work process: a qualitative study. Scand J Work Environ Heal. 2012;38(2):144-54.

10. Loisel P, Buchbinder R, Hazard R, Keller R, Scheel I, van Tulder M, et al. Prevention of work disability due to musculoskeletal disorders: the challenge of implementing evidence. J Occup Rehabil. 2005;15(4):507-24.

11. Young AE, Roessler RT, Wasiak R, McPherson KM, van Poppel MNM, Anema JR. A developmental conceptualization of return to work. J Occup Rehabil. 2005;15(4):557-68.

12. Neves RF, Nunes MO, Magalhães L. As interações entre os atores no retorno ao trabalho após afastamento por transtorno mental: uma metaetnografia. Cad Saude Publica. 2015;31(11):2275-90.

13. Thorne S, Jensen L, Kearney MH, Noblit G, Sandelowski M. Qualitative metasynthesis: reflections on methodological orientation and ideological agenda. Qual Health Res. 2004;14(10):1342-65.

14. Stergiou-Kita M, Grigorovich A, Tseung V, Milosevic E, Hebert D, Phan S, et al. Qualitative meta-synthesis of survivors' work experiences and the development of strategies to facilitate return to work. J Cancer Surviv. 2014;8(4):657-70.

15. Unit PHR. Critical Appraisal Skills Programme (CASP): making sense of evidence - 10 questions to help you make sense of qualitative research. [Internet]. Londres: Public Heal Resour Unit; 2006 [citado em 16 fev 2017]. Disponível em: http:// esquiresheffield.pbworks.com/f/WeChecklists.pdf.

16. Tong A, Sainsbury P, Craig J. Consolidated criterio for reporting qualitative research (COREQ): a 32item checklist for interviews and focus group. Int J Qual Heal Care. 2007;19(6):349-57.

17. Noblit GW, Hare RD. Meta-ethnography: synthesizing qualitativa studies. London: Newbury Park; 1988.

18. Munhall PL, editora. Nursing research: a qualitative perspective. 4 th ed. Sudbury: Jones amd Bartlett; 2007.

19. Halkett GKB, Arbon P, Scutter SD, Borg M. The phenomenon of making decisions during the experience of early breast cancer: original article. Eur J Cancer Care. 2007;16(4):322-30.

20. Nelms T. Phenomenological philosophy and research. In: Chesnay M, editor. Nursing research using phenomenology: qualitative designs and methods in nursing. New York: Springer Pub Com; 2014. p. 1-23.

21. Maunsell E, Brisson C, Dubois L, Lauzier S, Fraser A. Work problems after breast cancer: an exploratory qualitative study. Psychooncology. 1999;8(6):467-73.
22. Kennedy F, Haslam C, Munir F, Pryce J. Returning to work following cancer: a qualitative exploratory study into the experience of returning to work following cancer. Eur J of Cancer Care. 2007;16(1):17-25.

23. Johnsson A, Fornander T, Rutqvist LE, Olsson M. Factors influencing return to work: a narrative study of women treated for breast cancer. Eur J Cancer Care. 2010;19(3):317-23.

24. Nilsson M, Olsson M, Wennman-Larsen A, Petersson LM, Alexanderson K. Return to work after breast cancer: women's experiences of encounters with different stakeholders. Eur J Oncol Nurs. 2011;15(3):267-74.

25. Tiedtke C, Casterlé BD, Rijk A, Christiaens MR, Donceel P. Breast cancer treatment and work disability: patient perspectives. Breast. 2011;20(6):534-8.

26. Tiedtke C, Rijk A, Donceel P, Christiaens MR, Casterlé BD. Survived but feeling vulnerable and insecure: a qualitative study of the mental preparation for RTW after breast cancer treatment. BMC Public Health. 2012;12(1):1-13.

27. Nilsson MI, Olsson M, Petersson L, Alexanderson $\mathrm{K}$. Women 's reflections and actions regarding working after breast cancer surgery: a focus group study. Psychooncology. 2013;22:1639-44.

28. Tiedtke C, Casterlé BD, Donceel P, Rijk A. Workplace support after breast cancer treatment: recognition of vulnerability. Disabil Rehabil. 2015;37(19):1770-6.

29. Schutz A. Fenomenologia e Relações Sociais: textos escolhidos de Alfred Schutz. Wagner HR, editor. Rio de Janeiro: Zahar; 1979.

30. Sontag S. A doença como metáfora. Ramalho M, editor. Rio de Janeiro: Graal; 1984.

31. Tighe M, Molassiotis A, Morris J, Richardson J. Coping, meaning and symptom experience: a narrative approach to the overwhelming impacts of breast cancer in the first year following diagnosis. Eur J Oncol Nurs. 2011;15(3):226-32.

32. Saldanha JHS, Pereira APM, Neves RF, Lima MAG. Facilitadores e barreiras de retorno ao trabalho de trabalhadores acometidos por LER/DORT. Rev Bras Saúde Ocup. 2013;38(127):122-38.

33. Bury M. Doença crônica como ruptura biográfica Michael Bury. Tempus. 1979; edição esp:41-55.

34. Goffman E. Estigma: Notas sobre a manipulação da identidade deteriorada. 4a ed. Rio de Janeiro: LTC; 1988.

35. Munhall PL. Philosophical ponderings on qualitative research methods in nursing. Nurs Sci Q. 1989;2(1):20-8.

36. Goffman E. Ritual de interação: ensaios sobre o comportamento face a face. Petrópolis: Vozes; 2011. 
37. Arman M, Rehnsfeldt A. Living with breast cancer: a challenge to expansive and creative forces. Eur J Cancer Care. 2002;11(4):290-6.

38. Lima MAG, Trad LAB. "Circuloterapia”: uma metáfora para o enfrentamento da dor crônica em duas clínicas de dor. Physis Rev Saúde Coletiva. 2011;21(1):217-36.
39. Neves RF. Experiência e significado no retorno ao trabalho para trabalhadores com transtorno mental [tese]. Salvador: Universidade Federal da Bahia; 2016.

40. Rabelo MCM, Alves PCB. Significação e metáforas na experiência da enfermidade. In: Rabelo MCM, Alves PCB, Souza IMA, editores. Experiência de doença e narrativa. Rio de Janeiro: Fiocruz; 1999. p. 171-85. 